\title{
Heat Transfer of Ascending Cryomagma on Europa
}

2

\author{
Lynnae C. Quick ${ }^{\mathrm{a}, \mathrm{b}^{*}}$ and Bruce D. Marsh ${ }^{\mathrm{a}}$
}

4

5

${ }^{a}$ The Johns Hopkins University

6

Earth and Planetary Sciences Department

3400 North Charles Street

Baltimore, MD 21218

9

${ }^{\mathrm{b}}$ The Johns Hopkins University Applied Physics Laboratory

11100 Johns Hopkins Road

12

Laurel, MD 20723

13

*Corresponding Author: Lynnae C. Quick

lquick@psi.edu

16

Planetary Science Institute

1700 East Fort Lowell Rd., Suite 106

18

Tucson, AZ 85719

19

20

21

22

23 
1 Abstract: Jupiter's moon Europa has a relatively young surface (60-90 Myr on average),

2 which may be due in part to cryovolcanic processes. Current models for both effusive and

3 explosive cryovolcanism on Europa may be expanded and enhanced by linking the

4 potential for cryovolcanism at the surface to subsurface cryomagmatism. The success of

5 cryomagma transport through Europa's crust depends critically on the rate of ascent

6 relative to the rate of solidification. The final transport distance of cryomagma is thus

7 governed by initial melt volume, ascent rate, overall ascent distance, transport mechanism

8 (i.e., diapirism, diking, or ascent in cylindrical conduits), and melt temperature and

9 composition. The last two factors are especially critical in determining the budget of

10 expendable energy before complete solidification. Here we use these factors as

11 constraints to explore conditions under which cryomagma may arrive at Europa's surface

12 to facilitate cryovolcanism. We find that $1-5 \mathrm{~km}$ radius warm ice diapirs ascending from

13 the base of a $10 \mathrm{~km}$ thick stagnant lid can reach the shallow subsurface in a partially

14 molten state. Cryomagma transport may be further facilitated if diapirs travel along pre-

15 heated ascent paths. Under certain conditions, cryolavas transported from $10 \mathrm{~km}$ depths

16 in tabular dikes or pipe-like conduits may reach the surface at temperatures exceeding

$17250 \mathrm{~K}$. Ascent rates for these geometries may be high enough that isothermal transport is

18 approached. Cryomagmas containing significant amounts of low eutectic impurities can

19 also be delivered to Europa's surface by propagating dikes or pipe-like conduits.

\section{$21 \quad 1$ Introduction}

22 The surface of Jupiter's moon Europa is littered with many putative cryovolcanic

23 features (Fig. 1). While several of these features are thought to be evidence of effusive 
1 flows (Wilson et al., 1997; Figueredo et al., 2002; Fagents 2003), it is possible that low-

2 albedo deposits that surround lenticulae and lie along lineated features may be cryoclastic

3 mantlings deposited during explosive eruptions (Pappalardo et al., 1999; Fagents et al.,

4 2000; Quick et al., 2013). Moreover, lenticulae, chaotic terrain, and ridge and band

5 formation may be surface manifestations of subsurface cryomagmatic processes

6 associated with diapirism (Pappalardo et al., 1998, 1999; Rathbun et al., 1998; Collins et

7 al., 2000; Fagents et al., 2000; Figueredo et al., 2002; Prockter et al., 2002; Sotin et al.,

8 2002; Fagents, 2003; Tobie et al., 2003; Pappalardo and Barr, 2004; Han and Showman,

9 2005; Prockter and Schenk, 2005; Schmidt et al., 2011), diking, and sill emplacement

10 (Greenberg et al., 1998; Johnston and Montési, 2014; Michaut and Manga, 2014; Craft et

11 al., 2016).

12 Therefore, models for cryovolcanism on Europa (cf. Crawford and Stevenson,

13 1988; Wilson et al., 1997; Wilson and Head, 1998; Fagents et al., 2000; Fagents, 2003,

14 Quick et al., 2013) can be expanded and enhanced by linking observational evidence for

15 cryovolcanism at the surface to inferred subsurface cryomagmatic processes. Our work

16 attempts to provide this linkage by evaluating the heat transfer associated with specific

17 styles of cryomagma transport in Europa's interior. We aim to place rigorous bounds on

18 the tradeoffs between magma volume, ascent rate, and body geometry to achieve

19 cryovolcanism at the surface. In exploring these limits, constraints are also placed on the 20 physics of possible ascent mechanisms. 

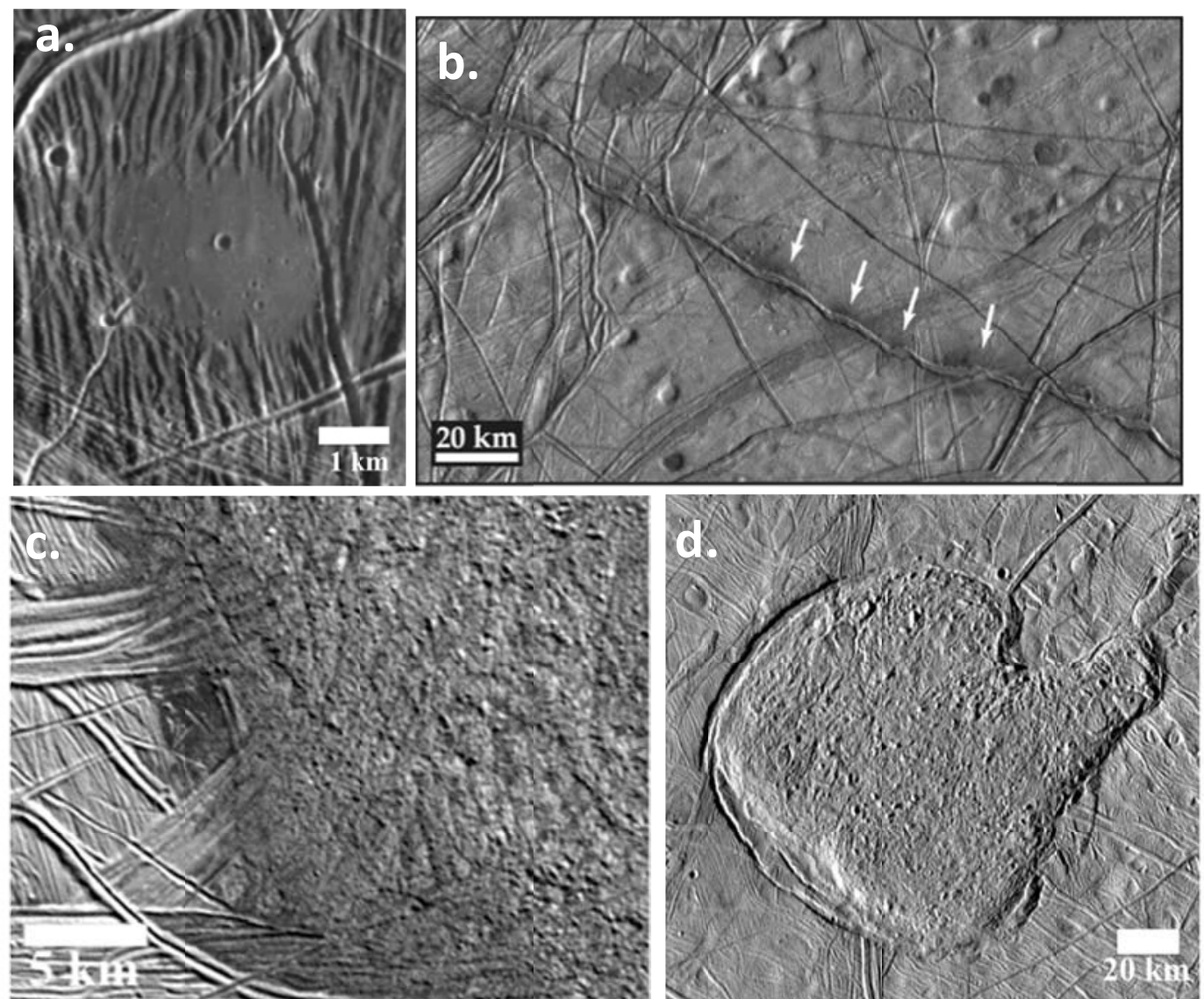

Figure 1. Putative cryovolcanic features on Europa include (a) a smooth circular feature located near the equator; (b)dark deposits along Rhadamanthys Linea; (c) putative flows at the edge of Thrace Macula; (d) Murias Chaos (The Mitten).

\subsection{Silicate Magma vs. Cryomagma}

A particularly striking contrast exists between cryovolcanism on icy satellites and

18 terrestrial volcanism. Terrestrial volcanism is distinct in three important ways: first,

19 because silicate magma has an adiabat that is much steeper than its liquidus, which itself

20 decreases with decreasing pressure or depth, terrestrial magmas tend to become strongly

21 superheated during ascent (e.g., Marsh, 2007); second, because silicate magmas are

22 multi-component systems, they possess a large crystallization interval between the

23 liquidus and solidus of 200 degrees or more. This interval produces a substantial sub-

24 liquidus corridor or "mush zone", consisting of a highly mobile mix of melt and crystals,

25 which can extrude onto the surface as lava (Fig. 2); third, silicate magmas are generally 
1 less dense than the country rock through which they must ascend. These three features of

2 silicate magmas ensure that the associated volcanism will be frequent and multifaceted.

3 Conversely, for warm ice and/or relatively pure water, which likely serve as

4 magmatic fluids on icy satellites like Europa, there is virtually no solidus-liquidus gap or

5 mush corridor, and the melting point slightly increases with decreasing pressure or depth.

6 As a result, ascending cryomagma tends to become supercooled. If the the liquidus is

7 crossed, the cryomagma has no pressure-temperature corridor of partial melt available,

8 and further ascent is immediately arrested by quenching (Fig. 2a). Furthermore, water

9 and other briny solutions that may serve as cryomagmas are negatively buoyant with

10 respect to the surrounding ice they must traverse. For this reason, these fluids may never

11 rise to the surface except for the case of pressure-driven ascent, or when significant

12 amounts of volatiles are included in solution (Crawford and Stevenson, 1988; Fagents et

13 al., 2000; Muñoz-Iglesias et al., 2014; Neveu et al., 2015). It is therefore essential to

14 determine the heat transfer parameters, transport mechanisms, and ascent rates that will

15 enable cryomagmas to: (1) successfully reach Europa's surface and (2) arrive before

16 undergoing thermal death by solidification.

17 

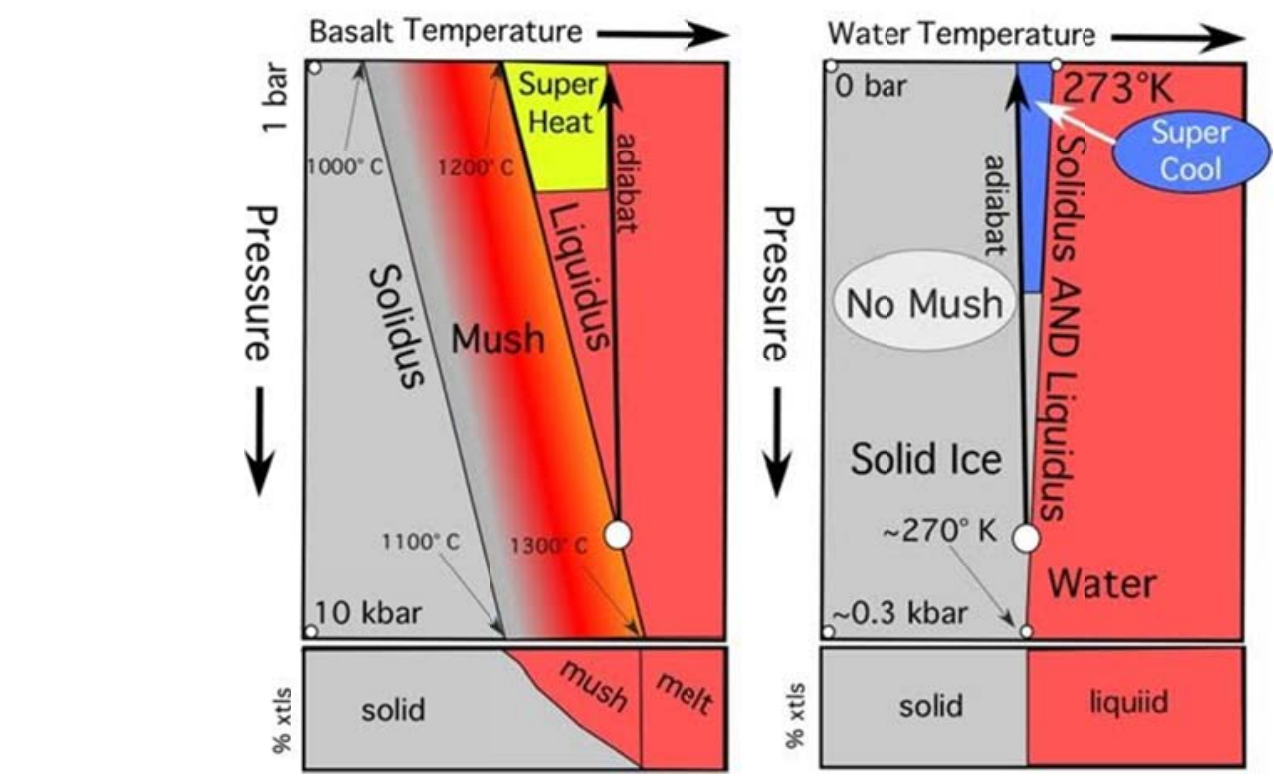

Figure 2a. Phase diagrams for basaltic magmas (left) and pure $\mathrm{H}_{2} \mathrm{O}$ cryomagmas (right). As basaltic magma rises to Earth's surface, it tends to become superheated and a mush zone of partial melt exists between the liquidus and solidus. Pure $\mathrm{H}_{2} \mathrm{O}$ cryomagmas tend to supercool in rising to the surface, and no mush zone exists. Note that $1 \mathrm{kbar}=100 \mathrm{MPa}$. (See also Fig. $2 \mathrm{~b}$ ).
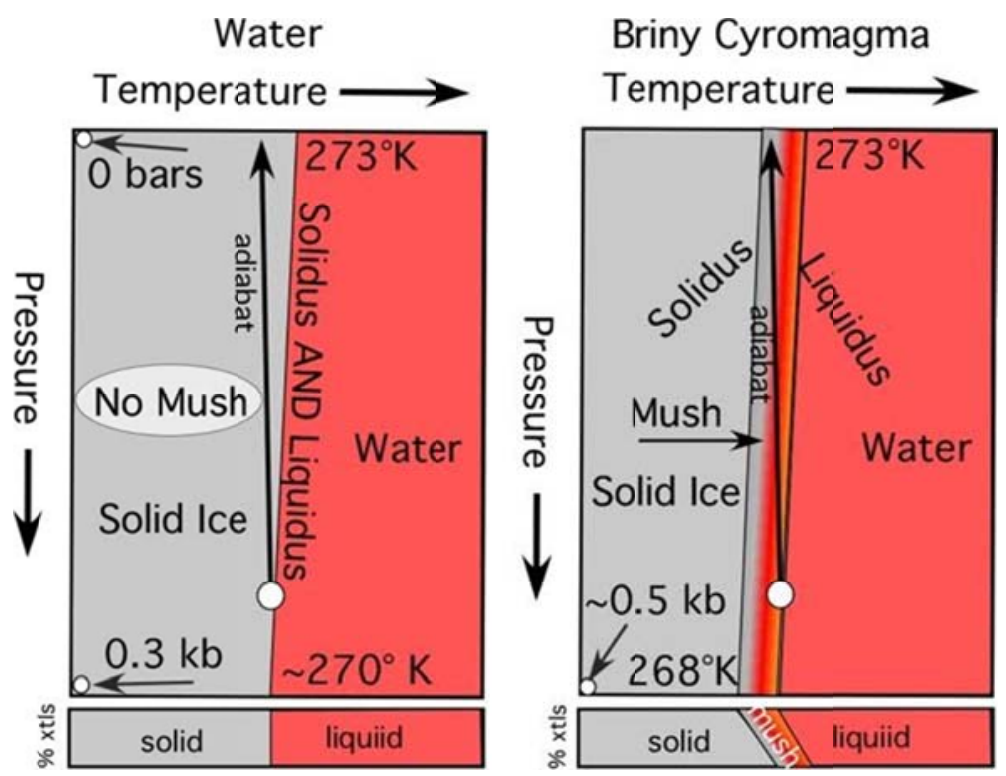

Figure 2b. The addition of low-eutectic salts or mineral acids may allow for slight superheating of cryomagmas on Europa, and the formation of a mush zone of partial melt. Note that $1 \mathrm{kbar}=100 \mathrm{MPa}$. 


\section{$1 \quad 1.2$ Briny Cryomagmas}

3 suggests the presence of hydrated minerals on Europa's surface. These minerals have

4 been identified as hydrated $\mathrm{Mg}$ - and $\mathrm{Na}$-sulfate salts and are mainly found near recently

5 disrupted surface areas and potential sites of extrusion of subsurface materials, i.e., along

6 lineae and near chaotic terrain (McCord et al., 1998; 1999). Linear mixture modeling has

7 confirmed that these species are prevalent in low-albedo surface units on Europa (Dalton

8 et al. 2005; Shirley et al., 2010; Dalton et al., 2012). It is possible that these hydrated

9 minerals originated in the subsurface ocean (Kargel et al., 2000; Spaun \& Head, 2001),

10 and previous workers have suggested that they may play a critical role in cryovolcanic

11 processes on Europa and other icy satellites (Kargel, 1991; Hogenboom et al., 1995;

12 Spaun and Head, 2001; Muñoz-Iglesias et al., 2013; 2014). Brown and Hand (2013) have

13 suggested that ocean-derived salts on Europa may be chlorides instead of sulfates. These

14 authors argue that salts such as $\mathrm{MgCl}_{2}, \mathrm{KCl}$, and $\mathrm{NaCl}$ may be endogenically produced

15 and quite abundant on Europa. If this is indeed the case, then chloride salts could also be

16 constituents of Europan cryomagmas.

17 Sulfuric acid and its hydrates have also been detected on Europa's surface

18 (Carlson et al., 1999; 2002; Dalton et al., 2005 and references therein). While there is

19 sufficient evidence that these species may have been exogenically emplaced (Carlson et

20 al., 1999; Dalton et al., 2007; 2012; 2013), previous work by Kargel et al. (2000) and

21 Pasek and Greenberg (2012) suggests that Europa's ocean could be highly acidic and that

22 sulfuric acid and its hydrates could be endogenic in origin. It has also been suggested that

23 low-albedo spots on Europa's surface could be products of small-scale flooding of 
1 sulfuric acid species (Fagents, 2003). Furthermore, it is possible that surface species on

2 Europa may be cycled into the interior by impact gardening (Cooper et al., 2001), crustal

3 cycling (Prockter and Pappalardo, 2000; Prockter et al., 2002; Kattenhorn and Prockter,

4 2014), and ridge formation (Greenberg et al., 2010), among other processes. This could

5 allow exogenically produced compounds like sulfuric acid to participate in geophysical

6 processes on the icy moon. Hence even if exogenically emplaced, it is still possible that

7 sulfuric acid species could participate in cryovolcanic processes on Europa. We therefore

8 consider the possibility that Europan cryomagmas could also consist of sulfuric acid

9 hydrates, albeit with the aforementioned caveats for exogenic emplacement.

10 The addition of any of these components to an $\mathrm{H}_{2} \mathrm{O}$-dominated cryomagma may

11 allow for a 5-75 $\mathrm{K}$ separation of the liquidus and solidus and the formation of a

12 cryomagmatic mush zone (Fig. 2b). As previously discussed in Section 1, and as

13 illustrated in Fig. 2a and b, when considering cryomagmatism on icy satellites, the

14 formation of this mush zone may be of critical importance, as low-eutectic contaminants

15 can aid in separating the liquidus from the solidus of cryomagmas and will ensure that a

16 partial melt zone exists (Fig. 2b).

17 Possible brine-containing aqueous solutions that may erupt on Europa as a result

18 of overpressurization of fluid reservoirs within the ice shell are listed in Table I. This

19 Table includes the properties of these solutions including their wt $\%$ of salt or acid,

20 eutectic temperatures, and densities as provided in Kargel (1991), McCarthy et al. (2007),

21 Green and Perry (2007) and Brady (2009). We note here that for certain species, it is only

22 with substantial concentrations of added salts or mineral acids that the eutectic is

23 significantly affected. This is the case for calcium chloride hexahydrate and the hydrated 
1 sulfuric acids, where eutectic temperatures may be as low as $223 \mathrm{~K}$ and $198 \mathrm{~K}$,

2 respectively at concentrations of 30-37 wt.\%. Conversely, adding smaller amounts of

3 hydrated $\mathrm{NaCl}, \mathrm{MgCl}_{2}, \mathrm{KCl}, \mathrm{MgSO}_{4}$, and $\mathrm{Na}_{2} \mathrm{SO}_{4}$ serves to reduce the eutectic by, at

4 most, about $34 \mathrm{~K}$ (see Table 1 and references therein).

5

6

Table 1. Possible Cryomagma Compositions

\begin{tabular}{|c|c|c|c|}
\hline $\begin{array}{c}\text { Aqueous Solution } \\
\text { (Hydrate }+\mathrm{H}_{2} \mathrm{O} \text { Phases) }\end{array}$ & $\begin{array}{c}\text { Hydrated Mineral } \\
\text { Wt.\% }\end{array}$ & $\begin{array}{l}\text { Density of } \\
\text { Solution, } \rho \\
\left(\mathbf{k g} / \mathbf{m}^{3}\right)\end{array}$ & $\begin{array}{c}\text { Eutectic } \\
\text { Temperature } \\
\text { (K) }\end{array}$ \\
\hline Water & N/A & 1000 & 273 \\
\hline Mirabilite & 4 wt. $\% \mathrm{Na}_{2} \mathrm{SO}_{4}-10 \mathrm{H}_{2} \mathrm{O}$ & 1038 & 272 \\
\hline Meridianiite & 17 wt. $\% \mathrm{MgSO}_{4}-11 \mathrm{H}_{2} \mathrm{O}$ & 1177 & 269.55 \\
\hline Epsomite & 20 wt. $\% \mathrm{MgSO}_{4}-7 \mathrm{H}_{2} \mathrm{O}$ & 1226 & 268 \\
\hline Bloedite & $\begin{array}{c}\mathrm{Na}_{2} \mathrm{Mg}\left(\mathrm{SO}_{4}\right)_{2}-4 \mathrm{H}_{2} \mathrm{O}: \\
16 \text { wt. } \% \mathrm{MgSO}_{4} ; 3 \text { wt. } \% \\
\mathrm{Na}_{2} \mathrm{SO}_{4}\end{array}$ & 1190 & 268 \\
\hline $\begin{array}{c}\text { Potassium Chloride } \\
\text { Hydrate }\end{array}$ & $19.9 \mathrm{wt} \% \mathrm{KCl}-\mathrm{nH}_{2} \mathrm{O}$ & $\sim 1132$ & 262 \\
\hline Hydrohalite & $23 \mathrm{wt} \% \mathrm{NaCl}-2 \mathrm{H}_{2} \mathrm{O}$ & $\sim 1200$ & 252 \\
\hline $\begin{array}{c}\text { Magnesium Chloride } \\
\text { Hydrate }\end{array}$ & $21 \mathrm{wt} \% \mathrm{MgCl}_{2}-\mathrm{nH}_{2} \mathrm{O}$ & $\sim 1200$ & 239.4 \\
\hline $\begin{array}{l}\text { Calcium Chloride } \\
\text { Hexahydrate }\end{array}$ & $30.2 \mathrm{wt} \% \mathrm{CaCl}_{2}-6 \mathrm{H}_{2} \mathrm{O}$ & 1282 & 223.2 \\
\hline Sulfuric Acid Hydrate & 35.6 wt. $\% \mathrm{H}_{2} \mathrm{SO}_{4}-6.5 \mathrm{H}_{2} \mathrm{O}$ & 1283 & 211 \\
\hline Sulfuric Acid Hydrate & 37 wt. $\% \mathrm{H}_{2} \mathrm{SO}_{4}-4 \mathrm{H}_{2} \mathrm{O}$ & 1290 & 198 \\
\hline
\end{tabular}

13 vertical, pipe-like conduits (e.g., Marsh, 1978; Marsh and Kantha, 1978; Marsh, 1982;

14 1984). These mechanisms have also been suggested for fluid transport on Europa by 15 various authors (e.g., Crawford and Stevenson, 1988; Pappalardo et al., 1998; Rathbun et 
1 al., 1998; Wilson and Head, 1997, 1998; Head and Pappalardo, 1999; Collins et al., 2000;

2 Figueredo et al., 2002; Sotin et al., 2002; Fagents, 2003; Pappalardo and Barr, 2004, 3 among others).

4 Diapirism may be initiated when a pocket of ice in a $250 \mathrm{~K}$ layer near the base of

5 the ice shell becomes tidally heated (Sotin et al., 2002) to a temperature near $269 \mathrm{~K}$. Once

6 heated, thermal buoyancy would cause the diapir to continue to rise (Rathbun et al.,

7 1998). Diapirs may also be generated by thermal convection in a ductile sublayer of ice

8 (McKinnon, 1999; Sotin et al., 2002; Mitri and Showman, 2005). In this case, buoyant

9 thermals would repeatedly rise from the base of the sublayer until steady Rayleigh-

10 Bernard convection is established (Marsh, 1989).

11 Dikes may be initiated when tidal effects generate stresses in Europa's ice shell

12 that open fluid-filled fractures. These fractures may extend from the underlying ocean

13 and would subsequently propagate upwards through the ice shell as they attempt to close

14 (Crawford and Stevenson, 1988; Matson et al., 2012). Dike propagation may also ensue

15 when crustal stresses acting on discrete fluid reservoirs or, excess pressures caused by

16 partial freezing of these reservoirs, generate fractures that propagate to the surface

17 (Fagents, 2003; Manga and Wang, 2007; Craft et al., 2013; 2016).

18 Pipe-like conduits are likely to be formed when rapidly ascending cryomagmas

19 melt and/or remove dike walls (Wylie et al., 1999; Carrigan, 2000). They may also form

20 when the distal, thinner ends of dikes rapidly seal off (cf. Daniels et al., 2012). This

21 sealing will cause melt flow to become increasingly concentrated into restricted regions

22 where it will become faster, more voluminous, and will be better able to stave off rapid

23 solidification (Petcovic and Dufek, 2005 and references therein; Wylie et al., 1999). 
To a large degree, the cooling rates of each of these transport mechanisms reflect

2 their surface area to volume ratios (Marsh, 1978; 1982). Diapirs, being roughly spherical,

3 have small surface area to volume ratios and thus cool relatively slowly (Marsh, 1978;

4 1982). Highly elliptical, tabular dikes, on the other hand, having large surface area to

5 volume ratios, cool quickly (Marsh 1978; 1982). Cooling rates for magma flowing in

6 cylindrical conduits is intermediate between the two.

\section{$7 \quad 2$ Methodology}

8 In sections 2.2-2.4 we present models for cryomagmatic ascent under three unique

9 conditions: the first model investigates heat transfer in cryomagmas that travel from the

10 base of the stagnant lid to the surface as diapirs of warm ice. The second and third models

11 investigate cryomagma ascent in propagating dikes and cylindrical conduits, respectively.

12 Here, we review the processes by which these transport mechanisms may occur, and

13 place bounds on their respective dimensions.

14 Diapirs are likely to warm the adjacent country ice as they rise, causing it to

15 become ductile. In this way they are able to traverse the rigid lid by causing the

16 surrounding ice to "flow" around them. Terrestrial magmatic diapirs are believed to move

17 through Earth's crust in this way, forming an ascent path by warming and mobilizing the

18 brittle rock around them (Marsh 1978; 1982 and section 4.1.1 for more details). We

19 envision that Europan diapirs tidally heated to $269 \mathrm{~K}$ arrive at the base of the stagnant lid

20 and may subsequently travel to the surface in this way.

21 Fagents (2003) showed that excess pressures caused by freezing of just $1 \%$ of

22 fluid in discrete reservoirs $10 \mathrm{~km}$ beneath Europa's surface was enough to drive the

23 eruption of fluids at the surface. Accordingly, it has been assumed that dikes and pipe- 
1 like conduits deliver fluids from isolated reservoirs at these depths to the surface.

2 Because the ascent of cryomagmatic solutions in dikes and cylindrical conduits is

3 pressure driven, buoyancy is not a problem. Hence cryolava delivered to the surface via

4 these mechanisms may be liquid water (Fagents, 2003), aqueous solutions containing

5 chloride or sulfate salts or mineral acids (Kargel, 1991; Hogenboom et al., 1995; Spaun

6 and Head, 2001; Muñoz-Iglesias et al., 2013; 2014), or slushy mixtures of water and ice

7 (Fagents, 2003; Miyamoto et al., 2005). The models presented here assume that

8 cryomagma delivered to Europa's surface via tabular dikes and pipe-like conduits is in

9 the form of liquid water initially at $273 \mathrm{~K}$.

10 Regardless of ascent mechanism, the significant factor in the present analysis is

11 not the exact means of sequestering cryomagmatic fluids, but rather that cryomagmatic

12 fluids very likely exist and are capable of being transported via the aforementioned

13 mechanisms. In this respect, the sizes of expected diapirs, dikes, and cylindrical conduits

14 are fundamentally important to estimate, as all results of the overall solidification time,

15 and thus transfer rates, depend critically on these measures.

16 In terms of determining the volume of magma involved in a typical cryovolcanic

17 event, estimates have been made based on the sizes of putative cryovolcanic features that

18 have been observed on the surface (e.g., see Figs. 1 \& 3). This is similar to the scheme

19 that is followed for terrestrial magmatism where the volumes of lavas, volcanoes, and

20 plutons place strong constraints on the modes and volumes of magma transport (e.g., see

21 Marsh, 1978; 2007; 2013; Crisp, 1984; Wylie et al., 1999; White et al., 2006; Annen,

22 2011; Barboni et al., 2015). According to Crisp (1984) and White et al. (2006), the ratio

23 of intruded to erupted magma in terrestrial systems is, on average, 5:1. Further, Europa's 
1 surface does not exhibit evidence of widespread cryovolcanism (Phillips et al., 2000;

2 Fagents, 2003; Miyamoto et al., 2005; Quick et al., 2013). For these reasons, we envision

3 that only a portion of available cryomagma in Europa's shallow subsurface will be

4 erupted during any cryovolcanic event. Hence, we assume that cryovolcanic features are

5 likely to provide minimum volume estimates.

6 Rathbun et al. (1998) suggested that diapirs responsible for the creation of domal

7 lenticulae on Europa (Fig. 3) may have had radii less than or equal to a few kilometers,

8 while Figueredo et al. (2002) suggest that Murias Chaos (Fig. 1d) may have been formed

9 when a 5-8 km diapir extruded and flowed out onto the surface. Previous workers have

10 asserted that lenticulae generally have diameters on the order of $10 \mathrm{~km}$ (Spaun et 1998;

11 1999; 2001; Pappalardo et al., 1998; Rathbun et al., 1998). Therefore, we assume

12 spherical diapirs that may have produced features on Europa's surface have radii between

131 and $5 \mathrm{~km}$. These dimensions are similar to those estimated for plutons in terrestrial

14 settings (Fyfe, 1970; Muroi, 1973; Marsh, 1978; 2000; Farina et al., 2010; Bunger and

15 Cruden, 2011; Nabelek et al., 2012; Marsh, 2013).

16 Wilson et al. (1997) considered dike widths between 1 and $30 \mathrm{~m}$ on Europa,

17 concluding that if putative flow lobes associated with Thrace Macula were

18 cryovolcanically emplaced, they may have been produced by cryomagmas ascending to

19 the surface in dikes 5-10 m wide. Recent work has shown that fractures capable of

20 bringing cryolavas to the surface of icy moons such as Enceladus may be at least $1 \mathrm{~m}$

21 wide (Neveu et al., 2015), while the width of an active fissure on the small moon has

22 been estimated to be $9 \mathrm{~m}$ (Goguen et al., 2009). Fagents (2003) considered conduits 1,10,

23 and $100 \mathrm{~m}$ wide capable of bringing cryomagmatic effusions to Europa's surface. She 
5 also noted that Europan fractures, which could transport cryomagmas to the surface, may

6 be $50-80 \mathrm{~m}$ wide (Fagents, 2003). We note however, that it may not be mechanically or

7 thermodynamically possible for such large fractures and conduits to be maintained on

8 Europa.

13 Based on this information, and to keep the models conservative, we take $r_{d}=2 \mathrm{~m}$.

14 Since conduits are likely to be produced when rapidly ascending cryomagmas melt and/or

15 remove dike walls (Carrigan, 2000), it is expected that these cylindrical passageways will

16 be several times wider than the eroded dikes/elastic cracks they were produced from.

17 Therefore, we take $r_{c}=6 \mathrm{~m}$ as the radius of the cylindrical conduit in the models

18 presented here. All cryomagmatic volumes considered are assumed to be reasonable

19 based on the volumes of potential eruptive features they may have produced on Europa's

20 surface.

14
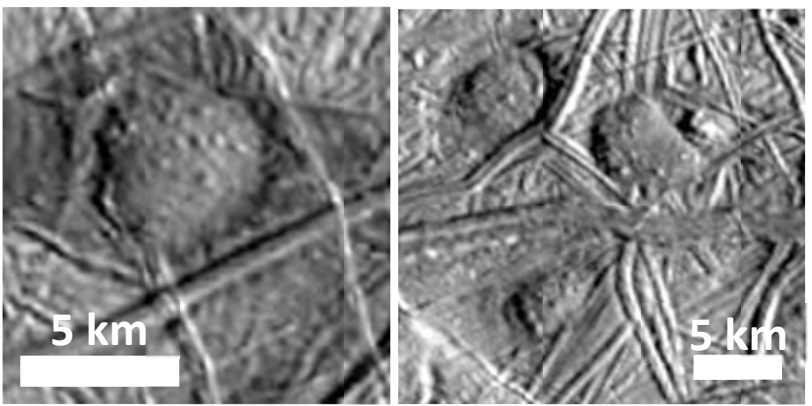

Figure 3. Domal lenticulae on Europa. In both images, illumination is from the right.

\section{$18 \quad 2.1$ Consistent Model Parameters}

20 The model assumptions discussed in this section have been applied to each form

21 of cryomagmatic ascent investigated.

22 Based on the work of Quick and Marsh (2015), we assume that the ice shell/ocean

23 interface on Europa is $\sim 30 \mathrm{~km}$ below the surface, which is in agreement with previous 
1 work suggesting an ice shell $\geq 20 \mathrm{~km}$ thick (Ojakangas and Stevenson, 1989; Rathbun et

2 al., 1998; Figueredo et al., 2002; Sotin et al., 2002; Schenk, 2002; Hussmann et al.,

3 2002). A $30 \mathrm{~km}$ thick ice shell is likely to convect (Pappalardo et al., 1998; McKinnon,

4 1999; Barr and Pappalardo, 2003; Tobie et al., 2003; Barr and Showman, 2009).

5 Cryomagma transport in all three cases is therefore explored in the presence of a

6 convecting sublayer of warm ice beneath a stagnant conducting lid (Fig. 4). Sotin et al.

7 (2002) suggested that for an approximately $35 \mathrm{~km}$ ice shell, the stagnant lid may be on

8 the order of $\sim 10 \mathrm{~km}$ thick, while Tobie et al. (2003) suggested that the stagnant lid may

9 be at least $35 \%$ of the total thickness of a $20-25 \mathrm{~km}$ ice shell. We have therefore assumed

10 a $30 \mathrm{~km}$ thick ice shell with a $10 \mathrm{~km}$ thick stagnant lid, and convective sublayer $20 \mathrm{~km}$

11 thick (Fig. 4).

12 Pappalardo et al. (1998) suggested that the temperature at the top of a convecting 13 sublayer in Europa would be approximately $197 \mathrm{~K}$, while the lower boundary

14 temperature would correspond to the ocean temperature of $273 \mathrm{~K}$ (Fig. 4). Once again,

15 the surface temperature is taken to be $100 \mathrm{~K}$. Hence the temperature gradient in the

16 stagnant lid would be approximately $9.7 \mathrm{~K} / \mathrm{km}$. Therefore, the temperature $T(z)$ at some

17 distance above the base of the stagnant conducting lid is of the form $T(z)=T_{o}-m z$, where

$18 T_{o}$ is the initial temperature of the cryomagma, $m=9.7 \mathrm{~K} / \mathrm{km}$ is the temperature gradient,

19 and $z$ is the distance above the base of the stagnant lid, which is situated at $z_{0}=10 \mathrm{~km}$

20 (Fig. 4). For simplicity, our models assume all cryomagmas ascend at a constant rate. We

21 also anticipate that cryomagmatic fluids which reach the surface at $200 \mathrm{~K}$ or more are

22 able to incite of cryovolcanism (Miyamoto et al., 2005; Goguen et al., 2013). $200 \mathrm{~K}$ is

23 therefore taken as the minimum temperature for which molten cryomagmas successfully 
1 arrive at Europa's surface. In the case of cryomagmas undergoing pressure-generated

2 transport via dike propagation and conduit ascent, this rather low temperature for aqueous

3 solutions contains the possibility of the cryomagma being a briny solution.

4 It should be noted that in each case, a constant thermal conductivity of $3.3 \mathrm{~W} / \mathrm{m}-\mathrm{K}$

5 was assumed for the ice shell (Barr and Showman, 2009). The effects of possible

6 compositional disparities in the ice shell were not taken into consideration because our

7 current knowledge of Europa's crustal compositional stratigraphy is too limited to

8 include such effects. For simplicity, the effects of cryomagma solidification at the walls

9 of dikes and cylindrical conduits (e.g., see Wylie et al., 1999; Carrigan, 2000; Daniels et

10 al., 2012) have also not been taken into consideration. In addition, we do not investigate

11 the effects that volatiles may have in delivering cryomagmatic fluids to the surface

12 (Crawford and Stevenson, 1988; Fagents et al., 2000; Muñoz-Iglesias et al., 2014).

13 Notwithstanding, given the limits of our understanding of cryomagmatic processes on icy

14 worlds, and on Europa's subsurface structure, the simplifications made here do not

15 prevent our models from placing useful bounds on heat transfer associated with

16 cryomagmatic ascent. Further should these effects become known, they could easily be

17 incorporated into the models presented here.

18 


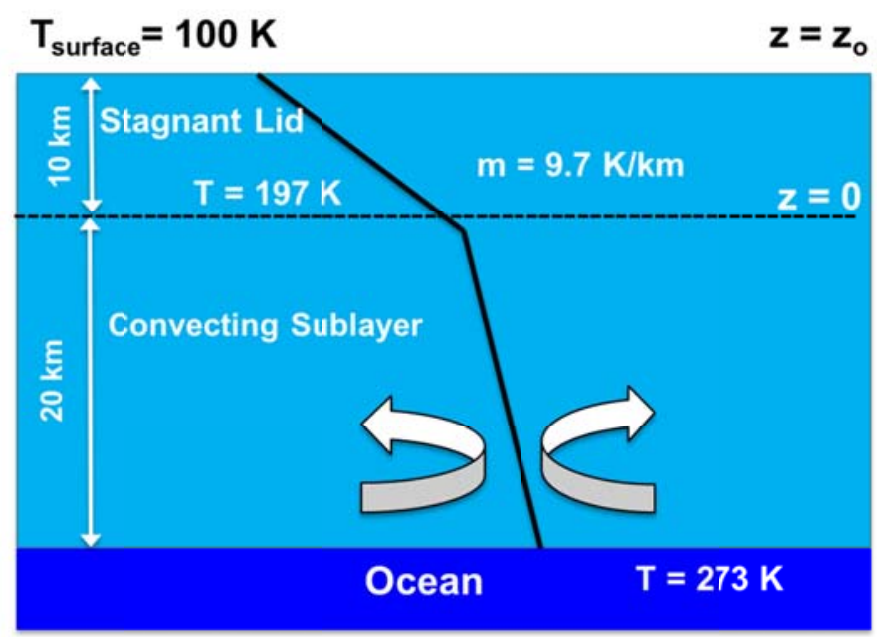

Figure 4. The structure of Europa's shell used in the models presented here. The shell consists of an approximately $10 \mathrm{~km}$ thick stagnant conducting lid atop a $20 \mathrm{~km}$ thick convecting sublayer. Adapted from McKinnon, 1999 with temperature values from Pappalardo et al., 1998.

\subsection{Diapiric Ascent}

11 Previous diapir models applied to the formation of domes and flow-like features on

12 Europa assumed that ascent occurred in an isothermal medium with a constant

13 background temperature (Rathbun et al., 1998; Figueredo et al., 2002). Conversely here,

14 the general formulation of Marsh $(1978 ; 1984)$ is followed for heat transfer in diapirs.

13 The total heat flux from an ascending magma body, $Q_{T}$, relative to the conductive

14 heat flux, $Q_{C}$, for the same magma body at rest, is defined as the Nusselt number, $N u$ :

$$
N u=\frac{Q_{T}}{Q_{C}}
$$

15 From (1) it is clear that $Q_{T}=N u * Q_{c}$, and by Fourier's Law:

$$
Q_{c}=\frac{A k_{c}}{L}\left[T-T_{m}(t)\right]
$$

20 is the conductive heat flux for a magma body with surface area, $A$, characteristic length

21 scale, $L$ (e.g., here $L$ equals the radius, $r_{s}$, of a spherical diapir), and average temperature,

$22 T$, located in a medium whose temperature far from the body is $T_{m}(z)=T_{m}(t)$. In (2), we

23 are considering the heat flux for a magma body at rest, so that $k_{c}$ is the thermal 
1 conductivity of the surrounding wall ice. Combining (1) and (2), the total heat flux of an

2 ascending magma body may be expressed as

$$
Q_{T}=N u \frac{A k_{c}}{L}\left[T-T_{m}(t)\right]
$$

4 The thermal energy, $E$, of the magma body is

$$
E=\rho_{m} c_{p_{m}} V T
$$

6 where $\rho_{m}$, and $c_{p_{m}}$ are the density and specific heat of the magmatic fluid, $V$ is the

7 volume of the magma body, and $T$ is the same as in (2). By energy conservation

8

$$
\frac{d E}{d t}=-Q_{T}
$$

$9 \quad$ Letting $J=N u\left(\frac{k_{c}}{\rho_{m} c_{p_{m}}}\right)\left(\frac{A}{L V}\right)$, (5) may be rewritten as

$$
\frac{d T}{d t}+J T=J T_{m}(t)
$$

11 Multiplying (6) by $e^{J t}$ yields $\frac{d T}{d t} e^{J t}+J T e^{J t}=J T_{m}(t) e^{J t}$ which may be alternatively

12 expressed as

$$
\frac{d}{d t}\left(T e^{J t}\right)=J T_{m}(t) e^{J t}
$$

14 According to the expression for the geotherm, $T_{m}(t)=T_{m}(z)=T_{o}-m z$. However, $z=v_{o} t$

15 where $v_{o}$ is ascent velocity, taken to be constant. The geotherm may therefore be 16 expressed as $T_{m}(t)=T_{m}(z)=T_{o}-m v_{o} t$. (7) now becomes

$$
\frac{d}{d t}\left(T e^{J t}\right)=J T_{o} e^{J t}-m v_{o} e^{J t}
$$

18 which may be rewritten as

$$
\left[T e^{J t}\right]_{o}^{t}=T_{o} \int_{o}^{t} e^{J t} J d t-\frac{m v_{o}}{J} \int_{o}^{t} J t e^{J t} d t
$$

20 Integration of (9) yields 


$$
T(t)=T_{o}-m v_{o} t+\frac{m v_{o}}{J}\left[1-e^{-J t}\right]
$$

2 As previously noted, $v_{o} t=z$, and the constant ascent velocity constraint means that $v_{o}=$

$3 v$. Thus, $1=v / v_{o}=(z / t) /\left(z_{0} / t_{o}\right)$, and $t / t_{o}=z / z_{o}$ so that $t=t_{o} z / z_{0}$. The temperature

4 distribution in an ascending diapir can therefore be expressed as

5

$$
T(t)=T_{o}-m z+m z\left[\frac{1-e^{-J t_{o} z / z_{o}}}{J t_{o}^{z} / z_{o}}\right]
$$

6 where $T_{o}=269 \mathrm{~K}$ is the diapir's initial temperature at base of the stagnant lid, $m=9.7$

$7 \mathrm{~K} / \mathrm{km}$, and $z_{o}=10 \mathrm{~km}$. Here $z=0$ refers to the base of the stagnant lid, and $z$ is any height

8 above the base so that $z=z_{o}$ at Europa's surface (Fig. 4). Moreover,

$$
J t_{o}=N u\left(\frac{k_{c}}{\rho_{m} c_{p_{m}}}\right)\left(\frac{A}{r_{s} V}\right) \frac{z_{o}}{v_{o}}
$$

10 is the non-dimensional parameter controlling the cryomagma cooling rate. In (12), $t_{o}$, the

11 total ascent time of the diapir, has been expressed as $z_{o} / v_{0} . N u$ is, again, the Nusselt

12 number, or the ratio of convective to conductive heat transfer in the diapir. For a liquid

13 sphere, $N u=0.46 \sqrt{\frac{v_{o} r_{s}}{\kappa_{m}}}=0.46(P e)^{1 / 2}\left(\right.$ Levich, 1962, p.408; Marsh, 1982). $P e=v_{o} L / \kappa_{m}$ is

14 the Péclet number, which is similar to $N u$ in that it too may be thought of as the ratio of

15 convective to conductive heat loss from the cryomagma as it ascends through the crust.

16 With a $100 \mathrm{~K}$ surface temperature and a $197 \mathrm{~K}$ bottom boundary temperature, the average

17 temperature of ice in the conducting lid is approximately $149 \mathrm{~K}$. Utilizing equation (15)

18 of Barr and Showman (2009) with $10^{14} \mathrm{~Pa} \mathrm{~s}$ as the dynamic viscosity of ice at $273 \mathrm{~K}$

19 returns an average viscosity of $2.4 \times 10^{23} \mathrm{~Pa}$ s for the conducting lid; a warm ice diapir at

$20269 \mathrm{~K}$ has a viscosity of $1.5 \times 10^{14} \mathrm{~Pa}$ s. According to Marsh (1982) and Weinberg and

21 Podlachikov (1995), the extreme viscosity contrast between the diapir and surrounding

22 country ice allows for the utilization of $N u$ for a liquid sphere here. Note also that for the 
1 warm ice diapir at $269 \mathrm{~K}, k_{m}=2.3 \mathrm{~W} / \mathrm{m}-\mathrm{K}$ (equation 5.6 of Hobbs, 1974), $c_{p_{m}}=1944$

$2 \mathrm{~J} / \mathrm{kg}-\mathrm{K}$ (Fig. 5.7 of Hobbs, 1974), and $\rho_{m}=918 \mathrm{~kg} / \mathrm{m}^{3}$, in agreement with the density

3 value for warm ice provided in Hobbs (1974) and Fagents (2003). Thermal diffusivity of

4 the cryomagma, $\kappa_{m}$, is therefore taken to be $1.3 \times 10^{-6} \mathrm{~m}^{2} / \mathrm{sec}$.

5 The rate of heat lost by diapirs as they move through the lithosphere can be

6 represented by various values of the dimensionless parameter $J t_{o}$ (Marsh and Kantha,

7 1978; Marsh, 1978;1982), where $J$ is a constant proportional to the rate of heat lost by

8 convection and conduction as diapirs ascend, and $t_{o}$, again, represents total ascent time to

9 the surface. From (12) it is clear that small values of $J t_{o}$ correspond to short total ascent

10 times, high ascent rates, and small quantities of heat loss en route to the surface.

11 By assigning a range of values for $J t_{o}$, the average temperature of diapirs moving

12 through the crust can be found without explicitly specifying the size of the diapir under

13 consideration. Diapir ascent velocity has been solved for as follows. Recall that $N u=$

$140.46 \sqrt{\frac{v_{o} r_{s}}{\kappa_{m}}}$, and from (12),Jto $=N u\left(\frac{k_{c}}{\rho_{m} c_{p_{m}}}\right)\left(\frac{A}{r_{s} V}\right) \frac{z_{o}}{v_{o}}$. Combining these expressions

15 yields

$$
J t_{o}=0.46 \sqrt{\frac{v_{o} r_{s}}{\kappa_{m}}}\left(\frac{k_{c}}{\rho_{m} c_{p_{m}}}\right)\left(\frac{A}{r_{s} V}\right) \frac{z_{o}}{v_{o}}
$$

17 where all constants are the same as before. Due to the constant ascent velocity

18 assumption, $v=v_{o}$, so that (13) becomes

$$
J t_{o}=0.46 \sqrt{\frac{v r_{s}}{\kappa_{m}}}\left(\frac{k_{c}}{\rho_{m} c_{p_{m}}}\right)\left(\frac{3}{r_{s}^{2}}\right) \frac{z_{o}}{v}
$$

20 which, after combining like terms, is

$$
J t_{o}=1.38\left(\frac{k_{c}}{\rho_{m} c_{p_{m}}}\right) \frac{z_{o}}{\sqrt{v \kappa_{m} r_{s}^{3}}}
$$


1 Squaring each side of (15) and solving for $v$ leads to

$$
v=1.9\left(\frac{k_{c}}{\rho_{m} c_{p_{m}}}\right)^{2} \frac{z_{o}{ }^{2}}{\left(J t_{o}\right)^{2} \kappa_{m} r_{s}^{3}}
$$

3 Inserting $k_{c}=3.3 \mathrm{~W} / \mathrm{m}-\mathrm{K}, \rho_{m}=918 \mathrm{~kg} / \mathrm{m}^{3}, c_{p_{m}}=1944 \mathrm{~J} / \mathrm{kg}-\mathrm{K}, \kappa_{m}=1.3 \times 10^{-6} \mathrm{~m}^{2} / \mathrm{s}$ and $z_{o}$

$4=10 \mathrm{~km}$ into (16), returns

$$
v \cong \frac{500}{r_{s}^{3}\left(J t_{o}\right)^{2}} m^{4} / s \approx 5\left(\frac{r_{s}}{0.215 m}\right)^{-3}\left(J t_{o}\right)^{-2} m^{-1}
$$

6 as an approximate expression for diapir ascent velocity. We reiterate here that $J t_{o}$ is an

7 adjustable parameter that is to be set. (17) illustrates that the velocities obtained from our

8 calculations correspond to a chosen value of $J t_{o}$. Note that from (14) $J t_{o}$ is simply equal to

$9 N u\left(\frac{3 k_{c}}{r_{s}^{2} \rho_{m} c_{p_{m}}}\right) \frac{z_{O}}{v}$. It is clear that $N u\left(\frac{3 k_{c}}{r_{s}^{2} \rho_{m} c_{p_{m}}}\right)$ represents the heat transfer timescale,

$10 t_{\text {trans }}$, while $\frac{z_{O}}{v}$ is total ascent time, $t_{\text {asc }}$. Thus (14) may be alternatively expressed as

$$
J t_{o}=t_{a s c} / t_{\text {trans }}
$$

\section{$12 \quad 2.3$ Cryomagmatic Ascent in Tabular Dikes}

13 As with terrestrial magmas, the Prandtl number $(\operatorname{Pr}=v / \kappa)$ of cryomagmas in

14 propagating dikes is expected to be large enough that a steady, fully developed velocity

15 profile may be assumed upon entrance into to the dike (Marsh, 1978). Owing to Europa's

16 geothermal gradient, however, the temperature of the ice shell continuously changes with

17 distance from the base of the stagnant lid. It is therefore unlikely that the temperature

18 profile will ever be fully developed. Since the temperature profile in the dike will never

19 become invariant with respect to position, the entire length of the dike is similar to an

20 extended thermal entrance region. It is therefore expected that the value of the Nusselt

21 number for the cryomagma continuously changes with distance from the base of the 
1 stagnant lid (Marsh, 1978; Chapter 4 of Mills, 1999). Accordingly, cryomagma

2 ascending in tabular dikes from subsurface fluid reservoirs can be effectively modeled as

3 fluid flow in vertical, flat ducts with varying wall temperatures. Following the

4 formulation in Sellars et al. (1955) and chapters 8 and 9 of Kays (1966) and Kays and

5 Crawford (1993), respectively, an expression for mean magma temperature in

6 propagating dikes can be derived (Quick, 2013), namely

$$
T=T_{o}+2 m z^{+}+\frac{9}{8} m \sum \frac{G_{n}}{\lambda_{n}^{4}}-\frac{9}{8} m \sum \frac{G_{n}}{\lambda_{n}^{4}} \exp \left(-\lambda_{n}^{2} \frac{8}{3} z^{+}\right)
$$

8 Here $T_{o}=273 \mathrm{~K}, m=9.7 \mathrm{~K} / \mathrm{km}$ and $z^{+}=\frac{z}{r_{d} P e}$ is the non-dimensional distance above the

9 base of the stagnant lid. Heat loss is once again controlled by the Péclet number, now

10 expressed as $P e=\frac{v r_{d}}{\kappa}$, where $r_{d}$ is dike half-width. Details leading to the derivation of

11 (19) may be found in chapter 8 of Kays (1966) and chapter 7 of Rohsenow and Hartnett

12 (1973) and Quick (2013). In accordance with Fagents (2003), we take $\kappa=5 \times 10^{-7} \mathrm{~m}^{2} / \mathrm{s}$

13 for pure water at $273 \mathrm{~K}$.

14 Large $\mathrm{Pe}$ means that fluid ascends at a high rate, resulting in a short ascent time

15 and a relatively small amount of heat loss. $G_{n}$ and $\lambda_{n}$ represent, respectively, numbers

16 resulting from eigenfunctions, and eigenvalues, found from the solution of a Sturm-

17 Liouville-type equation associated with flow in a flat duct. Values for $\lambda_{n}^{2}$ are listed in

18 Table II of Sellars et al. (1955), while values for $G_{n}$ in the flat duct geometry are taken

19 from Brown (1960). For completeness when $n=0,1,2,3, G_{n}=1.707,1.135,0.95$ and

200.845 (Brown, 1960) and corresponding $\lambda_{n}^{2}=2.779,32.11,93.45,186.9$ (Sellars et al.,

21 1955). Here, twice the total width of the dike has been taken as the hydraulic diameter 
1 (Chapter 9 of Kays and Crawford, 1993). Owing to their large surface area to volume

2 ratios, in comparison to diapirs, dikes must propagate at very high rates in order to arrive

3 at the surface before solidification.

$4 \quad 2.4$ Cryomagma Ascent in Pipe-Like Conduits

5 As previously mentioned, cylindrical conduits are usually generated by processes

6 associated with diapirism and diking. Here they are presented as secondary ascent

7 mechanisms formed via the continued passage of high velocity cryomagmas that erode

8 dike walls (Wylie et al., 1999; Carrigan, 2000).

9 Cryomagma ascending in pipe-like conduits is analogous to fluid undergoing

10 Poiseuille flow in cylindrical pipes where wall temperatures change continuously with

11 distance from the source. Hence mean magma temperature as a function of distance from

12 the top of fluid reservoir is represented by the following equation, which describes the

13 temperature of fluid flowing in a round tube with linearly varying wall temperature

$$
T=T_{o}+m z^{+}-8 m \sum \frac{G_{n}}{\lambda_{n}^{4}}+8 m \sum \frac{G_{n}}{\lambda_{n}^{4}} \exp \left(-\lambda_{n}^{2} z^{+}\right)
$$

15 (Sellars, et al., 1955; Chapter 8 of Kays, 1966; Chapter 9 of Kays and Crawford, 1993;

16 Quick, 2013). Here $T_{o}, m$, and $z$ are the same as in section 2.3, and $z^{+}=\frac{z}{r_{c} P e}$. Overall

17 heat loss is again controlled by $P e$, which may be expressed here as $P e=\frac{v r_{c}}{\kappa}$, where $r_{c}$ is

18 conduit radius and $\kappa=5 \times 10^{-7} \mathrm{~m}^{2} / \mathrm{s}$. As was the case for dikes, large $P e$ means that

19 magma ascends quickly through the conduit with a short ascent time and a relatively

20 small amount of heat loss. Values for and $G_{n}$ and $\lambda_{n}^{2}$ for a cylindrical geometry are listed 
1 in Table 8-3 of Kays (1966). For completeness, when $n=0,1,2,3, G_{n}=0.749,0.544$,

$2 \quad 0.463$ and 0.414 , and $\lambda_{n}^{2}=7.312,44.62,113.8,215.2$.

\section{$3 \quad 3$ Results}

$4 \quad$ Figures 5a-c show cooling curves for cryomagmas traversing Europa's ice shell.

5 Depending on ascent rate, cryomagmatic diapirs may reach the surface at various

6 temperatures (Fig. 5a and Table 2). In accordance with (11), diapirs rising through the

7 stagnant lid with $T_{o}=269 \mathrm{~K}$ may reach the surface at temperatures as high as $\sim 264 \mathrm{~K}$,

8 and as low as $186 \mathrm{~K}$ for $J t_{o}$ between 0.1 and 7, respectively. However, only diapirs with

$9 J t_{o} \leq 3$ will be able to reach the surface at temperatures greater than $200 \mathrm{~K}$ (Fig. 5a).

10 From (17), this corresponds to ascent velocities greater than $5.6 \times 10^{-8} \mathrm{~m} / \mathrm{s}$ for $1 \mathrm{~km}$

11 radius diapirs, and ascent velocities greater than $4.4 \times 10^{-10}$ for $5 \mathrm{~km}$ radius diapirs. Note

12 that for all $J t_{o}$ values considered here, diapirs will arrive within $3 \mathrm{~km}$ of the surface at

13 approximately $200 \mathrm{~K}$ (Fig. 5 and Table 2). It is worth noting that if diapirs incorporate

14 low-eutectic impurities as they travel through the ice shell (e.g., see Head and

15 Pappalardo, 1999; Schmidt et al., 2011), these species will serve as antifreezes that allow

16 them to travel more slowly without solidifying. Further, according to (11) and (17), for

17 any given $J t_{o}$, larger diapirs may ascend several orders of magnitude slower than their

18 smaller counterparts, yet still arrive at the surface at equivalent temperatures. This is

19 because low surface area to volume ratios help large diapirs hold on to heat more

20 efficiently than smaller ones. Table 2 contains ascent rates corresponding to 1 and $5 \mathrm{~km}$

21 radius diapirs for each $J t_{o}$ value investigated. Diapir temperatures halfway to the surface,

22 and at the surface, are also included for each $J t_{o}$ value. 
1 Cooling curves for cryomagmas that originate in fluid reservoirs near the base of the

2 stagnant lid and travel to the surface in propagating dikes or cylindrical conduits are

3 displayed in Figs. 5b \& c. According to (19), Pe must be close to 700 for cryomagmas

4 ascending in $4 \mathrm{~m}$ wide dikes to reach even half way to the surface at temperatures $\geq 200$

$5 \mathrm{~K}$ (Fig. 5b and Table 3). For $P e=1000$, fluids with temperatures greater than $200 \mathrm{~K}$ will

6 arrive within $3 \mathrm{~km}$ of the surface (Fig 5b). According to the Péclet number relation,

7 corresponding ascent velocities are $2.5 \times 10^{-4} \mathrm{~m} / \mathrm{s}$. Dikes must attain $P e=1300$ and

8 propagation rates of at least $3.4 \times 10^{-4} \mathrm{~m} / \mathrm{s}$ for the fluids within to be delivered to the

9 surface at $200 \mathrm{~K}$ (Fig. 5b). Conversely, $P e$ and $v$ must be very large, on the order of $10^{5}$,

10 and $2.6 \times 10^{-2} \mathrm{~m} / \mathrm{s}$, respectively, for fluids traveling in $4 \mathrm{~m}$ wide dikes to obtain

11 isothermal ascent. Such high $P e$ corresponds to flow in the turbulent regime for pure

12 water and briny aqueous solutions. Table 3 contains propagation and corresponding fluid

13 temperatures $50 \%$ of the way to the surface, and at the surface, for each $P e$ investigated.

14 Figure 5c shows that fluids ascending in $12 \mathrm{~m}$ wide pipe-like conduits must attain $P e$

$15=200$ to reach the very shallow subsurface at temperatures greater than $200 \mathrm{~K}$. For $P e=$

16300 and $v=2.5 \times 10^{-5} \mathrm{~m} / \mathrm{s}$, fluids will be delivered to the surface at temperatures around

$17220 \mathrm{~K}$ (Fig. 5c and Table 4). If $P e=10^{4}$, and an ascent rate of $8.3 \times 10^{-4} \mathrm{~m} / \mathrm{s} \mathrm{can} \mathrm{be}$

18 attained, fluids travelling in cylindrical conduits will ascend nearly isothermally. Note

19 that under the conditions explored here, isothermal ascent in a pipe-like conduit requires

$20 P e$ and $v$ about an order of magnitude less than for isothermal ascent in a tabular dike.

21 Table 4 contains ascent rates and corresponding fluid temperatures $50 \%$ of the way to the

22 surface, and at the surface, for each $P e$ investigated. 


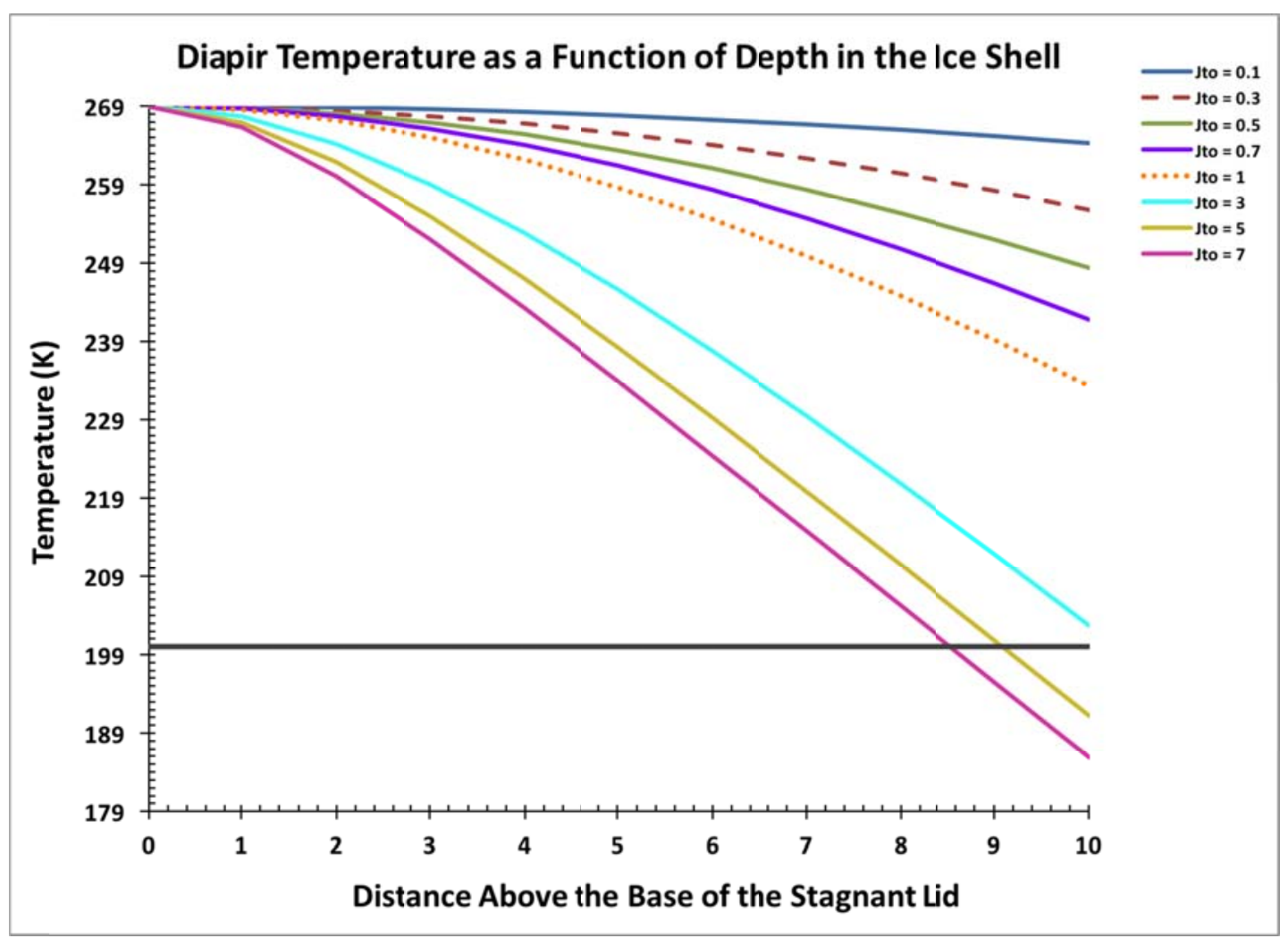

7 Figure 5a. Cooling curves for diapirs initially at $269 \mathrm{~K}$, travelling from the base of the stagnant lid to the 8 surface. In accordance with (11) and (17), the smallest $J t_{o}$ values correspond to the quickest ascent rates 9 and highest temperatures upon reaching the surface. The grey line represents the $200 \mathrm{~K}$ temperature mark required in our models for cryovolcanism to be incited at the surface by the successful ascent of cryomagmas to the surface. Also see Table 2. 


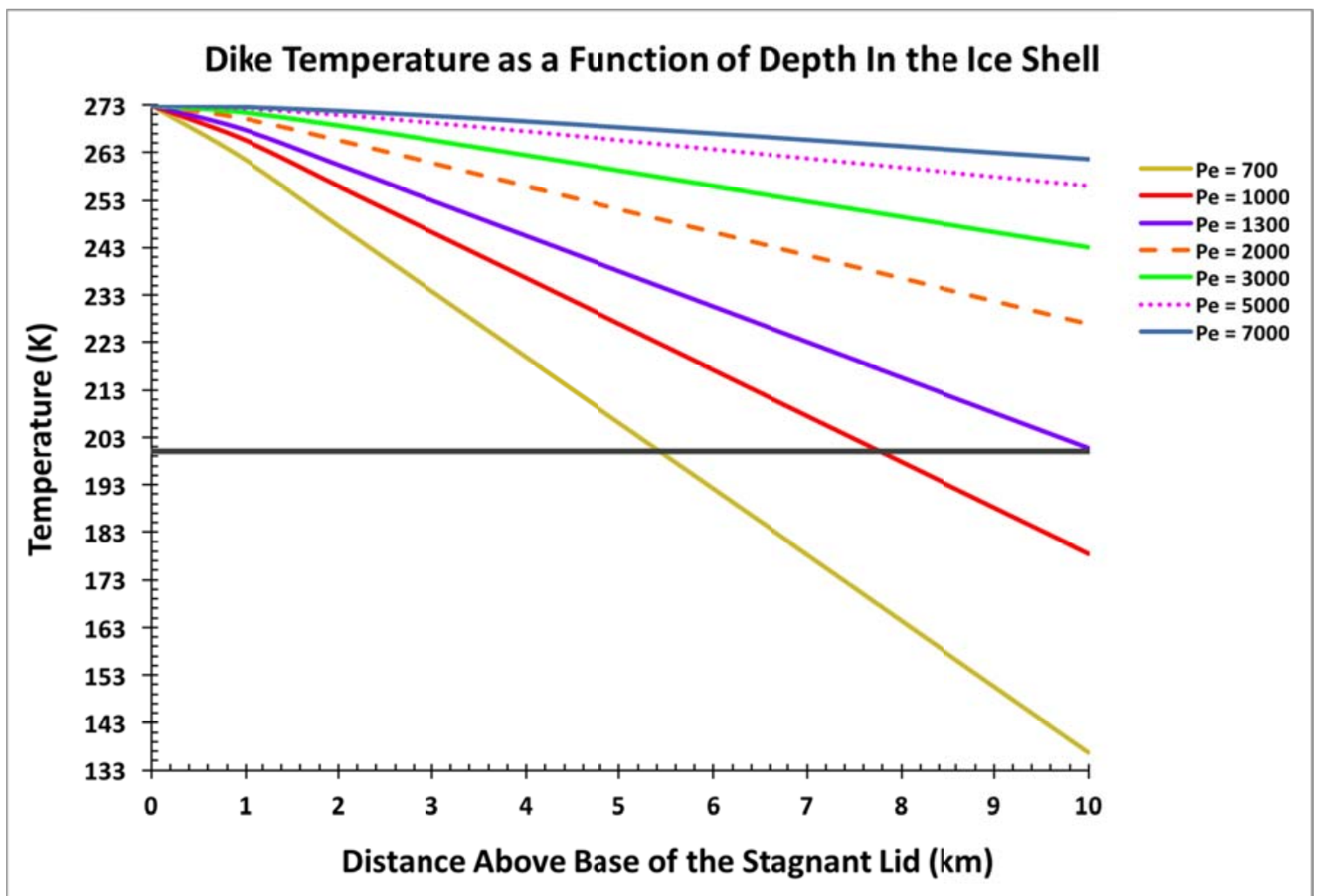

Figure $5 \mathrm{~b}$. Cooling curves for fluids initially at $273 \mathrm{~K}$ that originate near the base of the stagnant lid and 8 travel to the surface in tabular dikes $4 \mathrm{~m}$ wide. Here, large $P e$ correspond to a short total ascent time and

9 highest temperatures upon reaching the surface. Fluids reach the surface at $200 \mathrm{~K}$ for $P e=1300$. The grey 10 line represents the $200 \mathrm{~K}$ temperature mark required for successful ascent of cryomagmas to the surface.

11 Also see Table 3. 


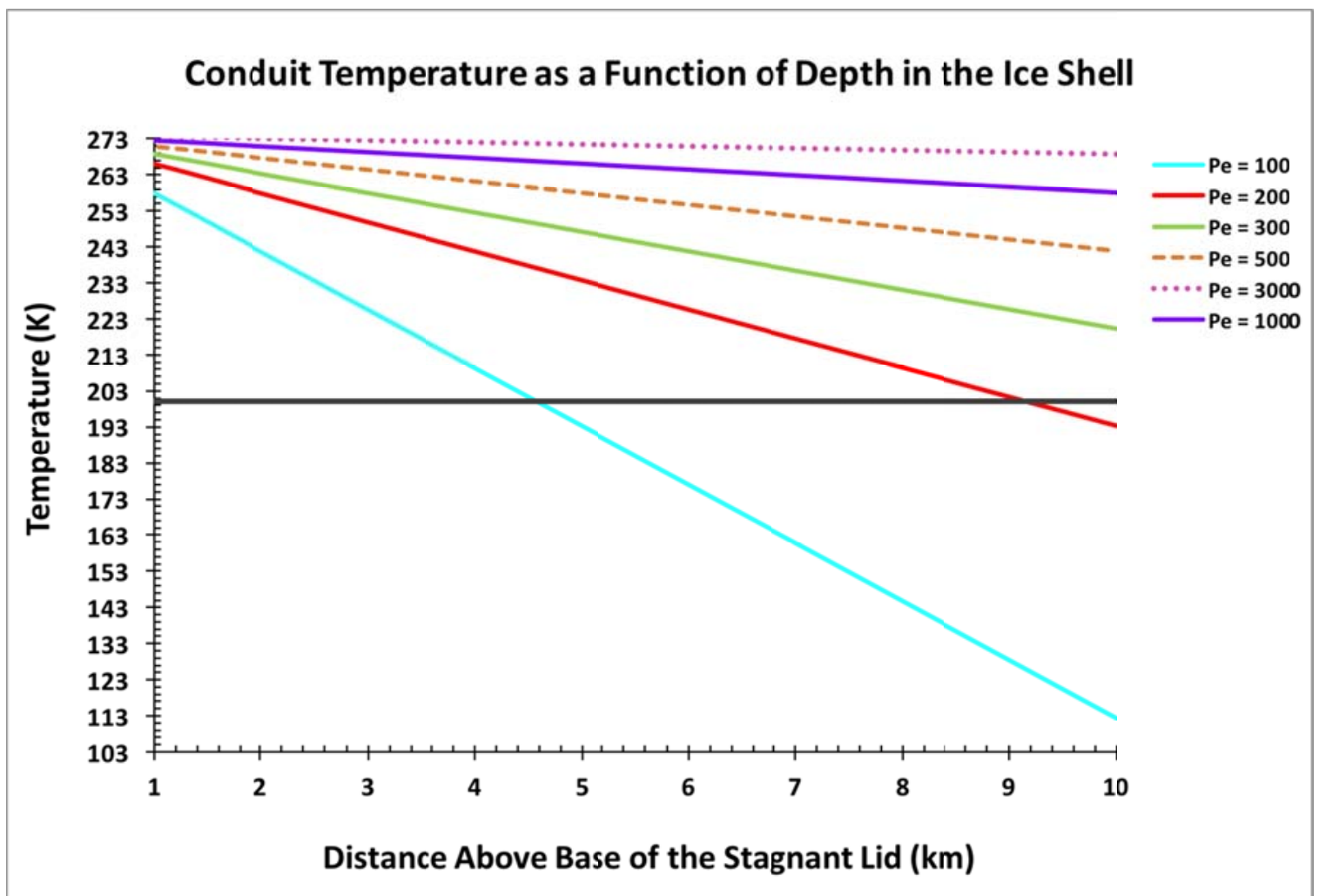

Figure 5c. Cooling curves for fluids originally at $273 \mathrm{~K}$ that travel to the surface in cylindrical conduits 12

$8 \mathrm{~m}$ wide. As is the case for dikes, large $P$ e corresponds to high ascent rates, short total ascent time, and high

9 fluid temperatures upon reaching the surface. Fluids reach $90 \%$ of the way to the surface at temperatures greater than $200 \mathrm{~K}$ for $P e=200$. The grey line represents the $200 \mathrm{~K}$ temperature mark required for successful ascent of cryomagmas to the surface. Also see Table 4. 
1 Table 2. Approximate temperatures and ascent rates for diapirs for each $J t_{o}$ value investigated. Diapir 2 temperatures $50 \%$ of the way to the surface, and at the surface, are displayed in the second and third 3 columns.

\begin{tabular}{|c|c|c|c|c|}
\hline & & & $\boldsymbol{r}=\mathbf{1} \mathbf{~ k m}$ & $\boldsymbol{r}=\mathbf{5} \mathbf{~ k m}$ \\
\hline $\boldsymbol{J t}_{\boldsymbol{o}}$ & $\boldsymbol{T} \mathbf{( K )}$ at $\boldsymbol{z}=\mathbf{5} \mathbf{~ k m}$ & $\boldsymbol{T} \mathbf{( K )} \mathbf{a t} \boldsymbol{z}=\mathbf{1 0 ~} \mathbf{~ k m}$ & $\boldsymbol{v} \mathbf{( m / s})$ & $\boldsymbol{v}(\mathbf{m} / \mathbf{s})$ \\
\hline 0.1 & 268 & 264 & $5 \times 10^{-5}$ & $4 \times 10^{-7}$ \\
\hline 0.2 & 267 & 260 & $1.3 \times 10^{-5}$ & $1 \times 10^{-7}$ \\
\hline 0.3 & 266 & 256 & $5.6 \times 10^{-6}$ & $4.4 \times 10^{-8}$ \\
\hline 0.4 & 264 & 252 & $3.3 \times 10^{-6}$ & $2.5 \times 10^{-8}$ \\
\hline 0.5 & 263 & 248 & $2 \times 10^{-6}$ & $1.6 \times 10^{-8}$ \\
\hline 0.6 & 262 & 245 & $1.4 \times 10^{-6}$ & $1.1 \times 10^{-8}$ \\
\hline 0.7 & 261 & 242 & $1 \times 10^{-6}$ & $8.2 \times 10^{-9}$ \\
\hline 0.8 & 260 & 239 & $7.8 \times 10^{-7}$ & $6.3 \times 10^{-9}$ \\
\hline 0.9 & 260 & 236 & $6.2 \times 10^{-7}$ & $5 \times 10^{-9}$ \\
\hline 1 & 259 & 233 & $5 \times 10^{-7}$ & $4 \times 10^{-9}$ \\
\hline 3 & 246 & 203 & $5.6 \times 10^{-8}$ & $4.4 \times 10^{-10}$ \\
\hline 5 & 238 & 191 & $2 \times 10^{-8}$ & $1.6 \times 10^{-10}$ \\
\hline 7 & 234 & 186 & $1 \times 10^{-8}$ & $8.2 \times 10^{-11}$ \\
\hline 9 & 231 & 183 & $6.2 \times 10^{-9}$ & $4.9 \times 10^{-11}$ \\
\hline 11 & 229 & 181 & $4.1 \times 10^{-9}$ & $3.3 \times 10^{-11}$ \\
\hline 13 & 228 & 179 & $3 \times 10^{-9}$ & $2.4 \times 10^{-11}$ \\
\hline 15 & 227 & 178 & $2.2 \times 10^{-9}$ & $1.8 \times 10^{-11}$ \\
\hline 20 & 225 & 177 & $1.3 \times 10^{-9}$ & $1 \times 10^{-11}$ \\
\hline
\end{tabular}

4

5

6

7

8

9

10

11

Table 3. Approximate temperatures and ascent speeds for fluids traveling in $4 \mathrm{~m}$ wide propagating dikes. Initial temperatures of these fluids were $273 \mathrm{~K}$. Propagation speeds were calculated using the Péclet number relation: $P e=v r_{d} / \kappa$, where $\kappa=5 \times 10^{-7} \mathrm{~m}^{2} / \mathrm{s}$ (Fagents, 2003).

\begin{tabular}{|c|c|c|c|}
\hline $\boldsymbol{P e}$ & $\boldsymbol{v}(\mathbf{m} / \mathbf{s})$ & $\boldsymbol{T}(\mathbf{K})$ at $\boldsymbol{z}=\mathbf{5} \mathbf{~ k m}$ & $\boldsymbol{T}(\mathbf{K})$ at $\boldsymbol{z}=\mathbf{1 0} \mathbf{~ k m}$ \\
\hline 500 & $1.3 \times 10^{-4}$ & 178 & 81 \\
\hline 700 & $1.8 \times 10^{-4}$ & 206 & 137 \\
\hline 1000 & $2.6 \times 10^{-4}$ & 227 & 178 \\
\hline 1300 & $3.4 \times 10^{-4}$ & 238 & 201 \\
\hline 2000 & $5.2 \times 10^{-4}$ & 251 & 227 \\
\hline 3000 & $7.8 \times 10^{-4}$ & 259 & 243 \\
\hline 5000 & $1.3 \times 10^{-3}$ & 266 & 256 \\
\hline 7000 & $1.8 \times 10^{-3}$ & 268 & 262 \\
\hline $2 \times 10^{4}$ & $5.2 \times 10^{-3}$ & 272 & 270 \\
\hline $1 \times 10^{5}$ & $2.6 \times 10^{-2}$ & 273 & 273 \\
\hline
\end{tabular}

12

13

14

15

16

17

18

19 
1 Table 4. Approximate temperatures and ascent speeds for fluids traveling in $12 \mathrm{~m}$ wide cylindrical

2 conduits. Initial temperatures of these fluids were $273 \mathrm{~K}$. Propagation speeds were calculated using the

3 Péclet number relation: $P e=v r_{c} / \kappa$, where $\kappa=5 \times 10^{-7} \mathrm{~m}^{2} / \mathrm{s}$ (Fagents, 2003).

\begin{tabular}{|c|c|c|c|}
\hline $\boldsymbol{P e}$ & $\boldsymbol{v}(\mathbf{m} / \mathbf{s})$ & $\boldsymbol{T}(\mathbf{K})$ at $\boldsymbol{z}=\mathbf{5} \mathbf{~ k m}$ & $\boldsymbol{T}(\mathbf{K})$ at $\boldsymbol{z}=\mathbf{1 0} \mathbf{~ k m}$ \\
\hline 100 & $8.3 \times 10^{-6}$ & 193 & 112 \\
\hline 200 & $1.7 \times 10^{-5}$ & 234 & 193 \\
\hline 300 & $2.5 \times 10^{-5}$ & 247 & 220 \\
\hline 500 & $4.2 \times 10^{-5}$ & 258 & 242 \\
\hline 700 & $5.8 \times 10^{-5}$ & 263 & 251 \\
\hline 1000 & $8.3 \times 10^{-5}$ & 266 & 258 \\
\hline 3000 & $2.5 \times 10^{-4}$ & 271 & 269 \\
\hline 5000 & $4.2 \times 10^{-4}$ & 272 & 271 \\
\hline $1 \times 10^{4}$ & $8.3 \times 10^{-4}$ & 273 & 272 \\
\hline
\end{tabular}

4

5

64 Discussion

7

8

9 values signify that the diapir, in effect, is inefficient in warming and softening the

10 surrounding lithospheric ice; as a result, it ascends very slowly and significant amounts of

11 heat are lost to the surrounding ice. Conversely, small $J t_{o}$ values signify that the diapir is

12 able to efficiently warm and soften the brittle ice surrounding it, enabling more rapid

13 ascent to the surface and retention of a significant fraction of its original heat (Marsh,

14 1982). We now turn to estimated ascent rates of terrestrial diapirs to determine if ascent

15 rates calculated in the previous section are reasonable.

16 In terrestrial settings, the drag experienced by an ascending diapir and its

17 associated velocity field are relatively unaffected by the properties of the diapirs

18 themselves, but rather by viscosity variations in the wall rock (Marsh, 1982; Weinberg

19 and Podladchikov, 1995). According to Grout (1945), in order for magma to reach the

20 surface successfully, the viscosity of the wall rock, and by extension, the drag that it

21 induces on the diapir, must be reduced along the diapir's periphery. To put it more 
1 simply, the velocity of an ascending diapir is determined by its ability to warm and soften

2 wall rock on its way to the surface.

3 As diapirs ascend, they are surrounded by thermal boundary layers. At the

4 external edge of the boundary layer wall rock viscosity is unchanged. However nearest

5 the diapir, the wall rock is heated and softened, and its viscosity substantially decreases

6 (Marsh, 1982; Weinberg and Podladchikov, 1995). This process is analogous to a hot

$7 \quad$ knife slicing through cold butter. According to Marsh (1978; 1982), the softened layer of

8 wall rock encasing diapirs as they travel is at most, $20-30 \%$ of the diapir's radius.

9 Assuming a softened layer $20 \%$ of the diapir's radius, this corresponds to adjacent

10 softened layers between $0.2-1 \mathrm{~km}$ thick on each side of diapirs $1-5 \mathrm{~km}$ in radius.

11 Assuming ice amenable to flow in Europa's subsurface must be warmed to at least $180 \mathrm{~K}$

12 (Barr and Showman, 2009) and applying equation (4-113) of Turcotte and Schubert

13 (2002), we find that it will take approximately 400 years for a diapir at $269 \mathrm{~K}$ to warm

$140.2 \mathrm{~km}$ of wall ice from $100 \mathrm{~K}$ to $180 \mathrm{~K}$. Conversely, it will take close to 10,000 years to

15 warm $1 \mathrm{~km}$ of adjacent wall ice to $180 \mathrm{~K}$. Here we have assumed that $k_{c}=3.3 \mathrm{~W} / \mathrm{m}-\mathrm{K}$

16 and $\rho_{i c e}=1000 \mathrm{~kg} / \mathrm{m}^{3}$; from Fig. 5.7 of Hobbs (1974), $c_{p}=1277 \mathrm{~J} / \mathrm{kg}-\mathrm{K}$ at $180 \mathrm{~K}$ (Fig.

175.7 of Hobbs). This returns $\kappa=3 \times 10^{-6} \mathrm{~m}^{2} / \mathrm{s}$ for use in Turcotte and Schubert's (2002)

18 equation (4-113). We can compare this to the time for softening wall rock adjacent to

19 dikes on Earth. Petcovic and Dufek (2005) have shown that wall rock melting in a $5 \mathrm{~m}$

20 thick layer adjacent to a $10 \mathrm{~m}$ wide dike can be initiated in less than 380 days, which

21 reflects the extreme heat carried by my terrestrial magmas.

22 Based on the timescale for conductive cooling $\left(t_{\text {cool }}=\mathrm{r}^{2} / \kappa\right)$, diapirs with $r_{s}=1 \mathrm{~km}$

23 will take about $3 \times 10^{4}$ years to completely cool, while those with $r_{s}=5 \mathrm{~km}$ will take 
1 approximately $8 \times 10^{5}$ years to cool. This means that both $1 \mathrm{~km}$ and $5 \mathrm{~km}$ radius diapirs

2 traversing a $10 \mathrm{~km}$ thick stagnant lid could successfully reach the surface. We hasten to

3 add, however, that with diapirs, in addition to the adjacent country ice that must be

4 softened, roof ice ahead of the advancing diapir must also be melted. We have not taken

$5 \quad$ this factor into account here.

6 Akin to terrestrial diapirs, Europan diapirs may be more likely to reach the surface

7 if they ascend paths that have been warmed and softened by the repeated passage of

8 previous generations of diapirs (Marsh 1978; 1982). Traversing a thermally insulated

9 path along which country ice and roof ice have already been processed may help diapirs

10 much smaller than those considered here reach the surface in a molten state. However, it

11 may take hundreds of thousands of years for these insulated chimneys to be established.

12 Once diapirism has been initiated it is possible that diapirs will ascend at different rates,

13 owing to the relative "warmth" of the lithospheric path they travel. On Earth, it is

14 common for magmas to travel rather quickly to the shallow subsurface and subsequently

15 wait for long periods of time before finally erupting (Marsh, 1978; Marsh and Kantha,

16 1978). Thus, variable ascent velocities are likely, but this involves a much greater

17 knowledge of both the details of the actual dynamics of ascent and the viscoelastic

18 properties of the ice shell than is presently known.

19 On Earth, diapirs ascending through un-preheated lithosphere are likely to travel

20 on the order of $10^{-8}$ to $10^{-9} \mathrm{~m} / \mathrm{s}$, while diapirs ascending paths that have been insulated by

21 the heat of previously ascending diapirs are likely to travel at rates between $10^{-7}$ and $10^{-6}$

$22 \mathrm{~m} / \mathrm{s}$ (Marsh, 1978; 1982). The viscosity of basaltic magma erupting at temperatures near

$231700 \mathrm{~K}$ is about $10 \mathrm{~Pa}-\mathrm{sec}$ (Spera, 2000), while the viscosity of Earth's solid mantle is 
$1 \quad 10^{21} \mathrm{~Pa}-\sec$ (Chapters $1 \& 6$ of Turcotte and Schubert, 2002). Hence the difference

2 between magma and mantle rock viscosity on Earth is, at most, about 21 orders of

3 magnitude. Assuming a minimum viscosity of $10^{14} \mathrm{~Pa}-\mathrm{sec}$ for warm ice on Europa,

4 equation (15) of Barr and Showman (2009) gives a viscosity on the order of $10^{33} \mathrm{~Pa}-\mathrm{sec}$

5 for lithospheric ice at $100 \mathrm{~K}$. Hence the maximum viscosity difference between warm ice

6 in diapirs, and the coldest part of Europa's lithosphere, is about 19 orders of magnitude.

7 Due to the similar viscosity differences between Earth's mantle rocks and magma and

8 Europa's brittle lithosphere and warm ice, we expect ascent velocities of diapirs of warm

9 ice moving through Europa's lithosphere to be comparable to ascent velocities of

10 terrestrial magma diapirs moving through Earth's mantle.

11 We therefore assume that the maximum ascent rate attainable for diapirs on

12 Europa is $10^{-7}-10^{-6} \mathrm{~m} / \mathrm{s}$. According to (17), this corresponds to $J t_{o}$ equal to $2.2-0.7$ for

13 diapirs with $1 \mathrm{~km}$ radii, and $J t_{o}$ equal to $0.2-0.06$ for diapirs with $5 \mathrm{~km}$ radii. From (11)

14 and (17), a $1 \mathrm{~km}$ radius diapir with $J t_{o}=2.2$ will reach the surface at $211 \mathrm{~K}$, while a $1 \mathrm{~km}$

15 radius diapir with $J t_{o}=0.7$ will arrive at the surface at $242 \mathrm{~K}$. Conversely for $J t_{o}=0.2$,

16 diapirs that are $5 \mathrm{~km}$ in radius would reach the surface at $260 \mathrm{~K}$, while their counterparts

17 with $J t_{o}=0.06$ would reach the surface at $266 \mathrm{~K}$. Hence if Europan diapirs were able to

18 attain these ascent rates, cryomagma could be successfully brought to the surface to

19 facilitate cryovolcanism. Extra heating and insulation provided by the use of pre-heated

20 ascent paths may allow diapirs to travel to the surface at these speeds.

21 As mentioned above, up to $1 \mathrm{~km}$ of surrounding country ice must be softened to

22 allow a $5 \mathrm{~km}$ radius diapir to pass through. Thus in order to traverse a $10 \mathrm{~km}$ thick brittle

23 layer of ice, $\sim 10$ times as much country ice must be processed. This means that it could 
1 take more than 10 successive diapirs to preheat a full $10 \mathrm{~km}$ ascent path through the

2 stagnant lid. This assumes that there are no nested diapirs and that each successive diapir

3 reaches a point closer to the surface than its progenitor. For the case of the $1 \mathrm{~km}$ radius

4 diapir, it could take as many as 50 successive diapirs to preheat the $10 \mathrm{~km}$ path. An

5 extensive treatment of the dynamics of warm ice diapirs ascending through an icy

6 lithosphere must be undertaken to further validate these conclusions. Such a treatment is

7 beyond the scope of this paper. However, preliminary calculations suggest that Europan

8 diapirs on the order of 5-10 km in radius will have ascent rates between $10^{-9}-10^{-7} \mathrm{~m} / \mathrm{s}$ if

9 traveling preheated ascent paths to the surface. This corresponds to $J t_{o}$ between 2-0.2 for

$105 \mathrm{~km}$ radius diapirs, and temperatures between $214-260 \mathrm{~K}$ upon reaching the surface.

11 Hence, successful cryomagma transport is possible. A more detailed analysis of the

12 dynamics of diapiric ascent on Europa will be the focus of a future manuscript.

\section{$13 \quad$ 4.1.2 Tabular Dikes and Cylindrical Conduits}

14 Dikes having a width of $4 \mathrm{~m}$ that propagate at $2.6 \times 10^{-2} \mathrm{~m} / \mathrm{s}$ could bring

15 cryomagmas to the surface under isothermal conditions. Our results indicate that the

16 same is true for $12 \mathrm{~m}$ wide cylindrical conduits that are able to attain ascent rates greater

17 than $8.3 \times 10^{-4} \mathrm{~m} / \mathrm{s}$. These velocities are reasonable in comparison to those estimated for

18 terrestrial magmas undergoing ascent in dikes and pipe-like conduits (Marsh, 1978).

19 Since excess pressure applied to fluid pockets in the subsurface is able to overcome the

20 negative buoyancy of fluids within, it is possible that ice slurries or briny cryomagmatic

21 solutions mentioned in Section 1.2 may be brought to the surface via diking or ascent in

22 cylindrical conduits. Reddish-brown areas on Europa could therefore represent places 
1 where tabular dikes or pipe-like conduits containing briny solutions have intersected with

2 the surface.

3 It must be noted that in terrestrial systems, pipe-like conduits are often parts of

4 intricate magmatic plumbing systems in well-developed, mature volcanic centers (Wright

5 and Klein, 2014). Diapirism and diking are more easily initiated and are commonly

6 observed in deeply eroded terrains. Hence depending on Europa's subsurface structure,

7 diapirism and diking may be the most likely mechanisms to bring cryomagmas to the

8 surface.

\section{Conclusions}

10 The areal extent and compositions of cryolavas erupted onto Europa's surface

11 could reveal a great deal about the moon's subsurface structure and evolution Information

12 that could be gleaned from cryolavas at the surface include the depth, composition, and

13 present state of subsurface cryomagma plumbing systems, as well as the dimensions of

14 diapirs, dikes, and pipe-like conduits that may have produced various surface features.

15 Tracking the cycling of cryomagma from the source to the surface could also shed light

16 on whether or not certain surface species such as $\mathrm{H}_{2} \mathrm{SO}_{4}, \mathrm{MgSO}_{4}$, etc., could be

17 endogenically produced or if they are strictly the results of exogenic processes. Further, if

18 cryomagmas ascending as diapirs originate at the ice-shell ocean interface, or if fluid

19 reservoirs in the ice shell are nothing more than stalled diapirs that contain oceanic

20 constituents, sampling of cryolava flows on the surface could reveal details concerning

21 the composition of the subsurface ocean. Bearing in mind the time it takes for them to

22 completely solidify, stalled diapirs could also represent habitable subsurface niches. 
1 These niches would be transient in nature; nevertheless, they would still be of

2 astrobiological interest.

3 On Earth, it is expected that diapirs must travel ascent paths that have been used

4 for millions of years by their predecessors in order to arrive at the surface before

5 solidification takes place. The same may be true on Europa. Hence, uplifts that may have

6 been created as a result of diapirism and areas where cryolavas may have erupted (Figs. 1

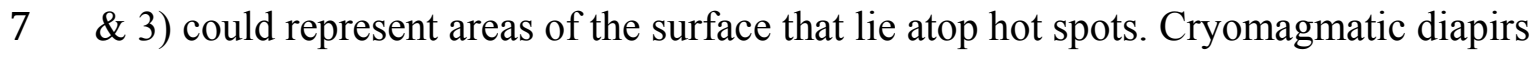

8 ascending at rates between $10^{-9}-10^{-6} \mathrm{~m} / \mathrm{s}$ through an approximately $10 \mathrm{~km}$ thick ice shell

9 will take $10^{2}-10^{4}$ years to arrive at the surface as cryolavas. Cryomagmatic dikes

10 travelling at speeds of $10^{-5}-10^{-2} \mathrm{~m} / \mathrm{s}$ would take 12 days to 32 years to travel from $10 \mathrm{~km}$

11 depths to the surface. A 12-day time constraint corresponds to isothermal ascent for the

12 dike geometry investigated here. On Earth, dikes have been inferred to travel at these

13 rates, and in some cases even faster, when accompanying volcanic events. Hence it is

14 possible that under special circumstances, fluids originating from $10 \mathrm{~km}$ depths in

15 Europa's subsurface may travel to the surface in dikes under isothermal conditions.

16 Any putative lava flows or cryovolcanic constructs on Europa that were not

17 present during the Galileo mission but are imaged by future Europa missions (e.g.

18 NASA's Europa Mission, or ESA's JUICE Mission) may have been recently brought to

19 the surface via diking or near surface diapirs that had yet to emerge during the Galileo

20 spacecraft's observations. In order to determine the primary means of cryomagma

21 transport on Europa, future missions should look for evidence of migrating hotspots

22 associated with areas of plate recycling and subduction, as well as for evidence of

23 eruptive vents at the surface. 


\section{Acknowledgements}

2 We gratefully acknowledge two anonymous reviewers whose suggestions helped to

3 improve the manuscript. L.C.Q. acknowledges funding from the Johns Hopkins

4 University Randolph W. Bromery Fellowship in Earth and Planetary Sciences and the

5 Johns Hopkins University Applied Physics Laboratory (APL) Graduate Student

6 Fellowship. B.D.M. acknowledges partial funding from The National Science

7 Foundation, Grant \# OPP 0440718.

8

\section{References}

10 Annen, C., 2011. Implications of Incremental Emplacement of Magma Bodies for

11 Magma Differentiation, Thermal Aureole Dimensions and Plutonism-Volcanism

12 Relationships. Tectonophysics 500, 3-10.

13 Barboni, M., Annen, C., Schoene, B., 2015. Evaluating the Construction and Evolution of

14 Upper Crustal Magma Reservoirs with Coupled U/Pb Zircon Geochronology and

15 Thermal Modeling: A Case Study from the Mt. Capanne Pluton (Elba, Italy).

$16 \quad$ Earth and Planetary Science Letters 432, 436-448.

17 Barr, A.C., Pappalardo, R.T., 2003. Numerical Simulations of Non-Newtonian

18 Convection in Ice: Application to Europa. Lunar and Planetary Science

$19 \quad$ Conference XXXIV. Abstract 1477.

20 Barr, A.C., Showman, A.P., 2009. Heat Transfer in Europa’s Ice Shell. In: Pappalardo,

21 R.T., McKinnon, W. B. and Khurana, K. (Eds.), Europa. University of Arizona

22 Press, Tucson, pp. 405-430.

23 Bird, R. B., Stewart, W. E., and Lightfoot E. N., 2007. Transport Phenomena, $2^{\text {nd }}$ Edition. 
John Wiley \& Sons, Inc., New York, NY.

2 Brady, J.B., 2009. Magma in a Beaker: Analog Experiments with Water and Various Salts or Sugar for Teaching Igneous Petrology. The Canadian Mineralogist 47, 457-471.

5 Brown, G.M., 1960. Heat or Mass Transfer in a Fluid in Laminar Flow in a Circular or

6 Flat Conduit. American Institute of Chemical Engineers Journal 6, 179-183.

7 Brown, M.E., Hand, K.P., 2013. Salts and Radiation Products on the Surface of Europa.

8 The Astronomical Journal 145, 110.

9 Bunger, A.P., Cruden, A. R., 2011. Modeling the Growth of Laccoliths and Large Mafic

10 Sills: Role of Magma Body Forces. Journal of Geophysical Research 116, B0223.

11 Carlson, R.W., Johnson, R.E., Anderson, M.S., 1999. Sulfuric Acid on Europa and the 12 Radiolytic Sulfur Cycle. Science 286, 97-99.

13 Carlson, R.W., Anderson, M.S., Johnson, R.E., Schulman, M.B., Yavrouian, A.H., 2002.

14 Sulfuric Acid Production on Europa: The Radiolysis of Sulfur in Water Ice. Icarus $15 \quad 157,456-463$.

16 Carrigan, C.R., 2000. Plumbing Systems. In: Houghton, B., McNutt, S.R., Rymer, H., 17 and Stix, J. (Eds.), Encyclopedia of Volcanoes. Academic Press, San Diego, CA, $18 \quad$ pp. 219-235.

19 Collins, G.C., Head, J.W., Pappalardo, R.T., Spaun, N.A., 2000. Evaluation of Models 20 for the Formation of Chaotic Terrain on Europa. Journal of Geophysical Research $21 \quad 105,1709-1716$.

22 Cooper, J.F., Johnson, R.E., Mauk, B.H., Garrett, H.B., Gehrels, N., 2001. Energetic Ion 23 and Electron Irradiation of the Icy Galilean Satellites. Icarus 149, 133-159. 
1 Craft, K.L., Patterson, G.W., Lowell, R.P., 2013. Sill Emplacement in Europa's Ice Shell

2 as a Driving Mechanism for Double Ridge Formation. $44^{\text {th }}$ Lunar and Planetary

3 Science Conference, Abstract 3033.

4 Craft, K.L., Patterson, G.W., Lowell, R.P., Germanovich, L., 2016. Fracturing and Flow:

5 Investigations into the Formation of Shallow Water Sills on Europa. Icarus,

6 doi:10.1016/j.icarus.2016.01.023.

7 Crawford, G.D., Stevenson, D.J., 1988. Gas-Driven Water Volcanism and the

$8 \quad$ Resurfacing of Europa. Icarus 73, 66-79.

9 Crisp, J. A., 1984. Rates of Magma Emplacement and Volcanic Output. Journal of

$10 \quad$ Volcanology and Geothermal Research 20, 177-211.

11 Daniels, K. A., Kavanagh, J. L., Menand, T., Sparks, R. S. J., 2012. The Shapes of Dikes:

12 Evidence for the Influence of Cooling and Inelastic Deformation. Geological

13 Society of America Bulletin 124, 1102-1112.

14 Dalton, J.B., Prieto-Ballesteros, O., Kargel, J.S., Jamieson, C.S., Jolivet, J., Quinn, R.,

15 2005. Spectral Comparison of Heavily Hydrated Salts with Disrupted Terrains on

$16 \quad$ Europa. Icarus 177, 472-490.

17 Dalton, J.B. III, 2007. Linear Mixture Modeling of Europa's Non-Ice Material Based on

18 Cryogenic Laboratory Spectroscopy. Geophysical Research Letters 34, L21205.

19 Dalton, J.B. III, Shirley, J.H., Kamp, L.W., 2012. Europa's Icy Bright Plains and Dark

20 Linea: Exogenic and Endogenic Contributions to the Composition and Surface

21 Properties. Journal of Geophysical Research 117, E03003.

22 Dalton, J.B., Cassidy, T., Paranicas, C., Shirley, J.H., Prockter, L.M., Kamp, L.W., 2013.

23 Exogenic Controls on Sulfuric Acid Hydrate Production at the Surface of Europa. 
Planetary and Space Science 77, 45-63.

2 Dombard, A. J., Patterson, G. W., Lederer, A. P., Prockter, L. M., 2013. Flanking Fractures and the Formation of Double Ridges on Europa. Icarus 223, 74-81.

4 Fagents, S.A., Greeley, R., Sullivan, R.J., Pappalardo, R.T., Prockter, L.M., 2000. Cryomagmatic Mechanisms for the Formation of Rhadamanthys Linea, Triple Band Margins, and Other Low-Albedo Features on Europa. Icarus 144, 54-88. Fagents, S.A., 2003. Considerations for Effusive Cryovolcanism on Europa: The Post Galileo Perspective. Journal of Geophysical Research 108, 5139.

9 Farina, F., Dini, A., Innocenti, F., Rocchi, S., Westerman, D. S., 2010. Rapid Incremental Assembly of the Monte Capanne Pluton (Elba Island, Tuscany) by Downward Stacking of Magma Sheets. Geological Society of America Bulletin 122, 14631479.

13 Figueredo, P.H., Chuang, F.C., Rathbun, J., Kirk, R.L., Greeley, R., 2002. Geology and Origin of Europa's “Mitten” Feature (Murias Chaos). Journal of Geophysical Research 107, 5026.

Fyfe, W.S., 1970. Some Thoughts on Granitic Magmas. In: Newall, G. and Rast, N. (Eds.), Geological Journal Special Issue 2, Mechanism of Igneous Intrusion.

19 Goguen, J. D., Buratti, J. B., Brown, R. H., Clark, R. N., Nicholson, P. D., Hedman, M. M., Howell, R. R., Sotin, C., Cruikshank, D. P., Baines, K. H., Lawrence, K. J.,

22 Fissure on Enceladus Measured with Cassini VIMS During the 14 April 2012 South Pole Flyover. Icarus 226, 1128-1137. 
1 Green, D.W., Perry, R.H., 2007. Perry's Chemical Engineers' Handbook, $8^{\text {th }}$ Edition. McGraw-Hill, New York, NY.

3 Greenberg, R., Geissler, P., Hoppa, G., Tufts, B.R., Durda, D.D., Pappalardo, R., Head, $4 \quad$ J.W., Greeley, R., Sullivan, R., Carr, M.H., 1998. Tectonic Processes on Europa: Tidal Stresses, Mechanical Response, and Visible Features. Icarus 135, 64-78.

6 Grout, F.F., 1945. Scale Models of Structures Related to Batholiths. American Journal of $7 \quad$ Science 243-A, Daly Volume, 260-284.

8 Han, L., Showman, A. P., 2005. Thermo-Compositional Convection in Europa's Icy $9 \quad$ Shell with Salinity. Geophysical Research Letters 32, L20201.

10 Head, J.W., Pappalardo, R.T., 1999. Brine Mobilization During Lithospheric Heating on

11 Europa: Implications for Formation of Chaos Terrain, Lenticula Texture, and

12 Color Variations. Journal of Geophysical Research 104, 27143-27155.

13 Hobbs, P.V., 1974. Ice Physics. Oxford University Press, New York, NY.

14 Hogenboom, D.L., Kargel, J.S., Gansan, J.P., Lee, L., 1995. Magnesium Sulfate-Water to

$15400 \mathrm{MPa}$ Using a Novel Piezometer: Densities, Phase Equilibria, and

16 Planetological Implications. Icarus 115, 258-277.

17 Hussmann, H., Spohn, T., Wieczerkowski, K., 2002. Thermal Equilibrium States of

18 Europa's Ice Shell: Implications for Internal Ocean Thickness and Surface Heat

19 Flow. Icarus 156, 143-151.

20 Johnston, S. A., and Montési, L. G. J., 2014. Formation of Ridges on Europa Above

21 Crystallizing Water Bodies Inside the Ice Shell. Icarus 237, 190-201.

22 Kargel, J.S., 1991. Brine Volcanism and the Interior Structures of Asteroids and Icy

23 Satellites. Icarus 94, 368-390. 
1 Kargel, J. S., Croft, S. K., Lunine, J. I., Lewis, J. S., 1991. Rheological Properties of

2 Ammonia-Water Liquids and Crystal-Liquid Slurries: Planetological

3 Applications. Icarus 89, 93-112.

4 Kargel, J.S., Kaye, J.Z., Head, J.W. III, Marion, G.M., Sassen, R., Crowley, J.K.,

5 Prieto-Ballesteros, O., Grant, S.A., Hogenboom, D.L., 2000. Europa's Crust and

6 Ocean: Origin, Composition and the Prospects for Life. Icarus 148, 226-265.

7 Kattenhorn, S. A., and Prockter, L. M., 2014. Evidence for Subduction in the Ice Shell of

$8 \quad$ Europa. Nature Geoscience 7, 762-767.

9 Kays, W.M., 1966. Convective Heat and Mass Transfer. McGraw Hill, New York, NY.

10 Kays, W.M., Crawford, M.E., 1993. Convective Heat and Mass Transfer. McGraw-Hill, $11 \quad$ New York, NY.

12 Levich, V.G., 1962. Physiochemical Hydrodynamics. Prentice-Hall, Englewood Cliffs, $13 \quad$ N.J.

14 Manga, M., Wang, C.Y., 2007. Pressurized Oceans and the Eruption of Liquid Water on

15 Europa and Enceladus. Geophysical Research Letters 34, L07202.

16 Marsh, B.D., 1978. On the Cooling of Ascending Andesitic Magma. Philosophical

17 Transactions of the Royal Society of London A, 288. 611-625.

18 Marsh, B.D., Kantha, L.H., 1978. On the Heat and Mass Transfer from an Ascending

19 Magma. Earth and Planetary Science Letters 39, 435-443.

20 Marsh, B.D., 1982. On the Mechanics of Igneous Diapirism, Stoping, and Zone Melting.

21 American Journal of Science 282, 808-855.

22 Marsh, B.D., 1984. Mechanics and Energetics of Magma Formation and Ascension.

23 In: Explosive Volcanism: Inception, Evolution and Hazards. National Academy 
Press, Washington, D.C., pp. 67-83.

2 Marsh, B.D., 1989. On Convective Style and Vigor in Sheet-Like Magma

3 Chambers. Journal of Petrology 30, 479-530.

4 Marsh, B.D., 2000. Magma Chambers. In: Houghton, B., McNutt, S.R., Rymer, H., and Stix, J. (Eds.), Encyclopedia of Volcanoes. Academic Press, San Diego, CA, pp. 191-206.

7 Marsh, B.D., 2007. Crystallization of Silicate Magmas Deciphered Using Crystal Size

8 Distributions. Journal of the American Ceramic Society 90, 746-757.

9 Marsh, B., 2013. On Some Fundamentals of Igneous Petrology. Contributions to

$10 \quad$ Mineralogy and Petrology 166, 665-690.

11 Matson, D.L., Castillo-Rogez, J.C., Davies, A.G., Johnson, T.V., 2012. Enceladus: A

12 Hypothesis for Bringing Both Heat and Chemicals to the Surface. Icarus 221, 53-

$13 \quad 62$.

14 McCarthy, C., Cooper, R.F., Kirby, S.H., Rieck, K.D., Stern, L., 2007. Solidification and 15 Microstructures of Binary Ice-I/Hydrate Eutectic Aggregates. American 16 Mineralogist 92, 1550-1560.

17 McCord, T.B., Hansen, G.B., Fanale, F.P., Carlson, R.W., Matson, D.L., Johnson, T.V.,

18 Smythe, W.D., Crowley, J.K., Martin, P.D., Ocampo, A., Hibbits, C.A.,

19 Granahan, J.C., and the NIMS Team, 1998. Salts on Europa's Surface Detected

20 By Galileo’s Near Infrared Mapping Spectrometer. Science 280, 1242-1245.

21 McCord, T. B., Hansen, G. B., Matson, D. L., Johnson, T. V., Crowley, J. K., Fanale, 22 F. P., Carlson, R. W., Smythe, W. D., Martin, P. D., Hibbits, C. A., Granahan, 23 J. C., Ocampo, A., 1999. Hydrated Salt Minerals on Europa's Surface from the 

Geophysical Research 104, 11287-11851.

3 McKinnon, W.B., 1999. Convective Instability in Europa's Floating Ice Shell.

$4 \quad$ Geophysical Research Letters 26, 951-954.

5 Michaut, C., and Manga, M., 2014. Domes, Pits, and Small Chaos on Europa Produced

6 by Water Sills. Journal of Geophysical Research: Planets 119, 550-573.

7 Mills, A.F., 1999. Heat Transfer. Prentice Hall, Upper Saddle River, N.J.

8 Mitri, G., Showman, A.P., 2005. Convective-Conductive Transitions and Sensitivity of a

9 Convecting Ice Shell to Perturbations in Heat Flux and Tidal Heating Rate:

10 Implications for Europa. Icarus 177, 447-460.

11 Miyamoto, H., Mitri, G., Showman, A.P., Dohm, J. M., 2005. Putative Ice Flows on

12 Europa: Geometric Patterns and Relation to Topography Collectively Constrain

13 Material Properties and Effusion Rates. Icarus 177, 413-424.

14 Muñoz-Iglesias, V., Bonales, L. J., Prieto-Ballesteros, O., 2013. pH and Salinity

15 Evolution of Europa's Brines: Raman Spectroscopy Study of Fractional

16 Precipitation at 1 and 300 bar. Astrobiology 13, 693-702.

17 Muñoz-Iglesias, V., Prieto-Ballesteros, O., Bonales, L. J., 2014. Conspicuous

18 Assemblages of Hydrated Minerals from the $\mathrm{H}_{2} \mathrm{O}-\mathrm{MgSO}_{4}-\mathrm{CO}_{2}$ System on

19 Jupiter's Europa Satellite. Icarus 125, 466-475.

20 Muroi, I., 1973. Results of Aeromagnetic Surveys Over Some Volcanoes and Calderas in

21 Japan. The Science Reports of the Tohoku University 21, 87-111.

22 Nabelek, P. I., Hofmeister, A. M., Whittington, A. G., 2012. The Influence of

23 Temperature-Dependent Thermal Diffusivity on the Conductive Cooling 
Rates of Plutons and Temperature-Time Paths in Contact Aureoles. Earth and Planetary Science Letters 317-318, 157-164.

3 Neveu, M., Desch, S. J., Shock, E. L., Glein, C. R., 2015. Prerequisites for Explosive

4 Cryovolcanism on Dwarf Planet-Class Kuiper Belt Objects. Icarus 246, 48-64.

5 Nimmo, F., and Giese, B., 2005. Thermal and Topographic Tests of Europa Chaos

6 Formation Models from Galileo E15 Observations. Icarus 177, 327-340.

7 Ojakangas, G.W., Stevenson, D.J., 1989. Thermal State of an Ice Shell on Europa. Icarus $8 \quad 81,220-241$.

9 Pappalardo, R.T., Head, J.W., Greeley, R., Sullivan, R.J., Pilcher, C., Schubert, G.,

10 Moore, W.B., Carr, M.H., Moore, J.M., Belton, M.J.S., Goldsby, D.L., 1998.

11 Geological Evidence for Solid-State Convection in Europa's Ice Shell. Nature $12 \quad 391,365-368$.

13 Pappalardo, R.T., Belton, M.J.S., Breneman, H.H., Carr, M.H., Chapman, C.R., Collins, 14 G.C., Denk, T., Fagents, S., Geissler, P.E., Giese, B., Greeley, R., Greenberg, R., 15 Head, J.W., Helfenstein, P., Hoppa, G., Kadel, S.D., Klaasen, K.P., 16 Klemaszewski, J.E., Magee, K., McEwen, A.S., Moore, J.M., Moore, W.B., 17 Neukum, G., Phillips, C.B., Prockter, L.M., Schubert, G., Senske, D.A., Sullivan, 18 R.J., Tufts, B.R., Turtle, E.P., Wagner, R., Williams, K.K., 1999. Does Europa 19 Have A Subsurface Ocean? Evaluation of the Geological Evidence. Journal of $20 \quad$ Geophysical Research 104, 24015-24055.

21 Pappalardo, R.T., Barr, A.C., 2004. The Origin of Domes on Europa: The Role of 22 Thermally Induced Compositional Diapirism. Geophysical Research Letters 31, $23 \quad$ L01701. 
1 Pasek, M. A., Greenberg, R., 2012. Acidification of Europa's Subsurface Ocean as a

2 Consequence of Oxidant Delivery. Astrobiology 12, 151-159.

3 Petcovic, H. L., Dufek, J. D., 2005. Modeling Magma Flow and Cooling in Dikes:

4 Implications for Emplacement of Columbia River Flood Basalts. Journal of

$5 \quad$ Geophysical Research 110, B10201.

6 Phillips, C. B., McEwen, A.S., Hoppa, G.V., Fagents, S.A., Greeley, R., Klemaszewski,

7 J.E., Pappalardo, R.T., Klaasen, K.P., Breneman, H.H., 2000. The Search for

8 Current Geologic Activity on Europa. Journal of Geophysical Research 105, $922579-22597$.

10 Prockter, L.M., Pappalardo, R.T., 2000. Folds on Europa: Implications for Crustal

11 Cycling and Accommodation of Extension. Science 289, 941-943.

12 Prockter, L.M., Head, J.W. III, Pappalardo, R.T., Sullivan, R.J., Clifton, A.E., Giese, B.,

13 Wagner, R., Neukum, G., 2002. Morphology of Europan Bands at High

14 Resolution: A Mid-Ocean Ridge-Type Mechanism. Journal of Geophysical

$15 \quad$ Research 107, 5028.

16 Prockter, L., Schenk, P., 2005. Origin and Evolution of Castalia Macula: An Anomalous

17 Young Depression on Europa. Icarus 177, 305-326.

18 Quick, L. C., 2013. Europa: Cryomagmatic Processes \& Cryovolcanic Surface

19 Expressions. Dissertation, Johns Hopkins University, 181 pages.

20 Quick, L.C., Barnouin, O.S., Prockter, L.M., Patterson, G.W., 2013. Constraints on the

21 Detection of Cryovolcanic Plumes on Europa. Planetary and Space Science 86,

$22 \quad 1-9$.

23 Quick, L.C., and Marsh, B.D., 2015. Constraining the Thickness of Europa's Water-Ice 
Shell: Insights from Tidal Dissipation and Conductive Cooling. Icarus 253, 16-24.

2 Rathbun, J.A., Musser, G.S. Jr., Squyres, S.W., 1998. Ice Diapirs on Europa: Implications

3 for Liquid Water. Geophysical Research Letters 25, 4157-4160.

4 Rohsenow, W. M., and Hartnett, J. P., 1973. Handbook of Heat Transfer. McGraw-Hill, $5 \quad$ New York, NY.

6 Schenk, P. M., 1991. Fluid Volcanism on Miranda and Ariel: Flow Morphology and

$7 \quad$ Composition. Journal of Geophysical Research 96, 1887-1906.

8 Schenk, P.M., 2002. Thickness Constraints on the Icy Shells of the Galilean Satellites

9 from a Comparison of Crater Shapes. Nature 417, 419-421.

10 Schmidt, B.E., Blakenship, D.D., Patterson, G.W., Schenk, P.M., 2011. Active Formation

11 of Chaos Terrain Over Shallow Subsurface Water on Europa. Nature 479, 502-

505.

13 Sellars, J., Tribus, M., Klein, J., 1955. Heat Transfer to Laminar Flow in A Round Tube

14 or Flat Conduit: The Graetz Problem Extended. The American Society of

15 Mechanical Engineers. New York, NY.

16 Shirley, J.H., Dalton, J. B. III, Prockter, L.M., Kamp, L.W., 2010. Europa’s Ridged

17 Plains and Smooth Low Albedo Plains: Distinctive Compositions and

18 Compositional Gradients at the Leading Side-Trailing Side Boundary. Icarus

$19210,358-384$.

20 Sotin, C., Head, J.W. III, Tobie, G., 2002. Europa: Tidal Heating of Upwelling Thermal

21 Plumes and the Origin of Lenticulae and Chaos Melting. Geophysical Research

$22 \quad$ Letters 29, 1233.

23 Spaun, N.A., Head, J.W., Collins, G.C., Prockter, L.M., Pappalardo, R.T., 1998. 
Conamara Chaos Region, Europa: Reconstruction of Mobile Polygonal Ice Blocks. Geophysical Research Letters 25, 4277-4280.

3 Spaun, N.A., Prockter, L.M., Pappalardo, R.T., Head, J.W., Collins, G.C., Antman, A., 4 Greeley, R., and the Galileo SSI Team, 1999. Spatial Distribution of Chaos and 5 Lenticulae on Europa. Lunar and Planetary Science Conference XXX, Abstract $6 \quad \# 1847$.

7 Spaun, N.A., Head, J.W. III, 2001. A Model of Europa's Crustal Structure: Recent 8 Galileo Results and Implications for an Ocean. Journal of Geophysical Research $9 \quad 106,7567-7576$.

10 Spera, F. J., 2000. Physical Properties of Magma. In: Houghton, B., McNutt, S.R.,

11 Rymer, H., and Stix, J. (Eds.), Encyclopedia of Volcanoes. Academic Press, San 12 Diego, CA, pp. 171-190.

13 Tobie, G., Choblet, G., Sotin, C., 2003. Tidally Heated Convection: Constraints on 14 Europa's Ice Shell Thickness. Journal of Geophysical Research 108, 5124.

15 Turcotte, D. L., Schubert, G., 2002. Geodynamics. Cambridge University Press, New $16 \quad$ York, N.Y.

17 Weinberg, R. F., Podladchikov, Y. Y., 1995. The Rise of Solid-State Diapirs. Journal of $18 \quad$ Structural Geology 17, 1183-1195.

19 White, S.M., Crisp, J. A., Spera, F. J., 2006. Long-term Volumetric Eruption Rates and 20 Magma Budgets. Geochemistry, Geophysics, Geosystems 7, Q03010.

21 Wilson, L., Head, J.W., Pappalardo, R.T., 1997. Eruption of Lava Flows on Europa:

22 Theory and Application to Thrace Macula. Journal of Geophysical Research 102, $239263-9272$. 
1 Wilson, L., Head, J.W., 1998. Europa Cryovolcanism: Ascent and Eruption of Magma and its Role in Resurfacing. Lunar and Planetary Science Conference XXIX. Abstract 1138.

4 Wright T.L., Klein F.W., 2014. Two Hundred Years of Magma Transport and Storage at Kilauea Volcano, Hawai'i, 1790-2008. U.S. Geological Survey Professional

$6 \quad$ Paper 1806, 240 p., 9 appendices.

7 Wylie, J. J., Helfrich, K. R., Dade, B., Lister, J. R., Salzig, J. F., 1999. Flow Localization 8 in Fissure Eruptions. Bulletin of Volcanology 60, 432-440.

9 Zolotov, M.Y., Kargel, J.S., 2009. On the Chemical Composition of Europa's Icy Shell, 10 Ocean, and Underlying Rocks. In: Pappalardo, R.T., McKinnon, W. B. and 11 Khurana, K. (Eds.), Europa. University of Arizona Press, Tucson, pp. 431-457.

12

13

14

15 